\title{
Formation and weathering assessment of oil-suspended sediment aggregates through a laboratory investigation
}

\author{
V. Suneel ${ }^{1}$ (I) $\cdot$ S. Sathish $\mathrm{Kumar}^{2} \cdot$ R. Balaji ${ }^{2} \cdot$ P. Vethamony ${ }^{3}$ \\ Received: 25 May 2020 / Accepted: 23 November 2020 / Published online: 4 January 2021 \\ (C) Springer-Verlag GmbH Germany, part of Springer Nature 2021
}

\begin{abstract}
Formation of oil-suspended sediment aggregates (OSAs) is believed to be one of the natural cleaning processes in the marine environment. In this study, we have investigated the formation processes of OSAs under different mixing periods (continuous mixing and with the addition of sediments in between), oil-sediment ratios (1:1, 1:2 and 2:1) and crude oils (Arabian Light (AL), Kuwait (KW) and Murban $(\mathrm{MB})$ ). The results revealed that size of OSAs significantly increased (up to $\approx 1.41 \mathrm{~mm}$ ) with the addition of sediments. Aggregates (total 36) were extracted for n-alkanes and polycyclic aromatic hydrocarbons to quantify and assess their weathering and toxic levels. The maximum n-alkane depletion was $84 \%$ (111-02), 94\% (212-02) and 84\% (321-02) and PAH depletion was $\approx 72 \%$ (111-02), 79\% (212-02) and 81\% (311-03) for the OSAs of AL, KW and MB crude oils, respectively, for the different samples considered, indicating that n-alkanes were depleted relatively higher than the PAHs. The highest depletion of both n-alkane and PAHs has occurred in OSAs of 10-h continuous mixing. The depletion of both n-alkane and PAHs reduced after the addition of sediments, however, escalated the growth of OSAs, resulting in bigger size OSAs. The concentration of PAHs of all 36 OSAs is greater than $5000 \mathrm{ng} / \mathrm{g}$, indicating very high PAH pollution. Though the formation of OSAs helps in cleaning the spill sites, the carcinogenic threat to the marine ecosystem caused by these OSAs cannot be ignored.
\end{abstract}

Keywords Oil spill $\cdot$ Oil-suspended sediment aggregates $\cdot$ Weathering $\cdot$ Polycyclic aromatic hydrocarbons $\cdot n$-alkanes

\section{Introduction}

Oil spills in the sea are of great concern in terms of their damage to the marine ecosystem and loss of economy; cleaning of spill-affected sites is also a challenging task. The global demand for oil is increasing day by day, leading to increase in oil exploration and transportation across seas and oceans, and this may also result in increase of marine oil spills. Oil spill accidents are a serious threat to the marine ecosystem, and the authorities are more concerned about containing the

Responsible editor: Vedula VSS Sarma

V. Suneel

suneel@nio.org

1 CSIR - National Institute of Oceanography, Dona Paula, Goa 403 004, India

2 Indian Institute of Technology Bombay, Powai, Mumbai 400 076, India

3 Environmental Science Center, Qatar University, P.O Box: 2713, Doha, Qatar spilled oil in a very effective way. Many studies have been carried out on removal of spilled oil from the surface by using chemical dispersants. However, the efficiency of dispersants and their effects on the marine environment is still not understood properly. One school of thought is that oil-SPM aggregates that are formed naturally can be used to clean the spilled oil effectively. Polycyclic aromatic hydrocarbons (PAHs) are one of the carcinogenic components of oils, and they pose severe threat to the environment because of their toxicity, carcinogenic and mutagenic properties (Deng et al. 2013). The Deepwater Horizon (DWH) oil spill occurred in the Gulf of Mexico during 20 April-15 July 2010 released $\approx 4.9$ million barrels of oil (Liu et al. 2012; Sammarco et al. 2013), and created a huge environmental damage. Another incident on 28 January 2017 off Chennai coast, India, due to collision of 2 vessels resulted in $\approx 196$ metric tonnes of bunker fuel oil spill (grade 6) into the Bay of Bengal waters (Han et al. 2018), and seriously damaged the coast.

In general, the spilled oil in the sea undergoes various weathering processes such as evaporation, emulsification, dispersion, dissolution, photo-oxidation, sedimentation, adhesion to minerals and biodegradation. Eventually, some of 
these processes lead to formation of tar balls (Aghajanloo and Pirooz, 2011, Fingas, 2011, NRC, 2003). These processes are mainly controlled by oil type and hydrodynamic and environmental conditions. The type of weathering processes can be determined using the diagnostic ratios of select components, primarily from aliphatic and aromatic compounds (Wade et al. 2016). During vertical dispersion, the oil droplets interact with suspended particulate matter (SPM) to form oil SPM aggregates (OSAs) (Spaulding 1988, Khelifa et al. 2002, 2005, Payne et al. 2003, Ajijolaiya et al. 2006, Sun and Zheng 2009, Gong et al. 2014, Hospital et al. 2016). OSAs are also termed as oil mineral aggregates (OMAs) (Lee et al. 1998). Many laboratory experiments were performed on OSA formation in a controlled environment for better understanding of the dynamics involved (Payne et al. 2003, Khelifa et al. 2007, Li et al. 2007, Loh et al. 2014, Sørensen et al. 2014, Sun et al. 2014, Moreira et al. 2015, Gustitus et al. 2017). It is considered that formation of OMA/OSA is a natural remediation process of oiled shorelines (Owens and Lee, 2003). For example, the natural cleansing of shorelines was impacted by the spills of Exxon Valdez (Bragg and Owens, 1995; Bragg and Yang, 1995) and Sea Empress (Lee et al. 1997). It is well recognized that the formation of natural OSAs is effective to clean the spilled sites in the marine environment only to an extent based on weathering, and availability of sediment particles (Sun et al. 2014). Sun et al. (2014) studied the OSA formation with respect to different mixing energies and indicated that OSAs are formed rapidly when sufficient mixing energy and suspended particulate matter (SPM) are available in the water column. Under moderate sediment concentrations and realistic mixing energy levels, formation of OSA may contribute to dispersion of 20 to $37 \%$ of the spilled oil within the first $2 \mathrm{~h}$ of the spill.

Based on the previous incidents on oil spill accidents, Lee and Page (1997) have postulated that $13 \%$ of the spilled oil can enter into sub-tidal regions. It is observed that aggregation between oil and suspended particulate matter occurs in the coastal region, where the SPM is rich (Sun et al. 2014). The interaction between the dispersed oil droplets with the SPM has a significant role in transporting bulk quantities of spilled oil (Bandara et al. 2011) and polycyclic aromatic hydrocarbons (PAHs) to the sub-tidal sediments (Payne et al. 2003). Hospital et al. (2016) identified $\approx 30,000$ tons of spilled oil which was deposited in the inter-tidal sediments in the form of OSAs after the Braer oil spill incident in 1993. Numerous studies are conducted on oil-SPM interaction, but it remains complex to understand the dynamics of the process in a quantitative manner. Several numerical studies revealed that up to $65 \%$ of the spilled oil can be removed as OSAs from the water column (Gong et al. 2014).

During the oil-SPM interaction, highly soluble monocyclic aromatic compounds and volatile $\mathrm{C}_{1}-\mathrm{C}_{10}$ aliphatic compounds are partitioned into the marine water column where they subsequently evaporate and biodegrade, while intermediate and higher molecular weight aliphatic and PAH compounds remain associated with the OSAs (Payne et al. 2003). The ultimate fate of these OSAs in the natural marine environment and their toxic or carcinogenic levels are poorly studied. There is a high possibility that some of these OSAs may be buried in the costal sediments, and, if they are washed to the shore, may be buried on high tide lines of the beaches or washed back to the sea if appropriate cleaning measures are not taken in a timely manner. Thus, the carcinogenic hydrocarbons that are trapped in the OSAs may return to the marine environment.

Polycyclic aromatic hydrocarbons (PAHs) are carcinogenic, mutagenic and toxic to the marine environment and to the human. Their emergence to the environment has become a serious concern to the stake-holders and researchers (Cao et al. 2009, Karami et al. 2012). The sources of PAHs are broadly categorized into three types: pyrogenic-derived from the incomplete combustion; petrogenic-caused by the petroleum sources; and diagenic-derived from plant materials and precursors (Zakaria et al. 2002). PAHs comprised of two to six fused aromatic rings in which $\mathrm{PAH}$ compounds with two and three rings (low molecular weight) have a significant acute toxicity, whereas some of the PAH compounds with more than three rings (high molecular weight) are carcinogenic (Yan et al. 2016, Yin et al. 2015, Zhang et al. 2014). Due to low volatility and low water solubility, PAHs in marine environment tend to accumulate in finegrained sediments and suspended particles, which eventually impact benthic organisms. They can also enter the food chain. The dietary intake of contaminated sea food is considered one of the major sources of human exposure to PAHs (Zelinkova and Wenzl, 2015; Liu et al. 2013). The exposure of human to PAHs may enhance the risk of cancer and other adverse health effects (Rengarajan et al. 2015). Several studies have evidenced that the PAH compounds such as benz(a)pyrene, benz(a)anthracene and chrysene are carcinogenic even if they are present in low concentrations (Al-Yakoob et al. 1993, Al-Yakoob et al. 1994). Therefore, in order to understand the environmental impacts of OSAs, the hydrocarbon contamination needs to be quantified (Reddy and Quinn, 1999, Sammarco et al. 2013). In this background, the present study is taken up with the following objectives: (i) to investigate the formation of OSAs through laboratory experiments under different mixing conditions such as $5 \mathrm{~h}$ and $10 \mathrm{~h}$ (continuous mixing) and $10 \mathrm{~h}^{*}$ and $20 \mathrm{~h}^{*}$ (addition of sediments) with different oil sediment ratios $(1: 1 ; 1: 2$ and $2: 1)$ and different crude oils (AL, KW and MB) and (ii) to assess the weathering of OSAs based on the n-alkane and PAH compounds and to measure their toxicity or carcinogenicity levels. 


\section{Materials and methods}

\section{Chemicals}

All the solvents including n-hexane, dichloromethane, methanol and acetone used in this experiment were in chromatographic grade and authentic standards for n-alkanes $\left(\mathrm{C}_{8}-\mathrm{C}_{40}\right)$ and $\mathrm{PAH}$, and these were purchased from Sigma-Aldrich, USA. A 100-200 mesh silica gel was baked at $400{ }^{\circ} \mathrm{C}$ for $4 \mathrm{~h}$, cooled, activated at $200^{\circ} \mathrm{C}$ overnight and deactivated with $5 \%$ of milli-Q water.

\section{Experimental methods}

Modified Khelifa et al. (2007) procedure was used to simulate OSA formation. The details of experiments are given in the following section. Details of typical experimental setup are given in Fig. S1 and Table S1.

\section{OSA formation experiment}

The methodology of OSA preparation is described in Khelifa et al. (2007) and Sun et al. (2010). In this work, the methodology was modified as follows: OSAs were prepared under a controlled temperature environment using reciprocating shaker at a constant mixing rate. Artificial sea water with $33 \%$ o salinity was prepared using Sigma-Aldrich synthetic sea salts (Guyomarch et al., 2002; Venosa and Holder, 2013). Two hundred fifty millilitres of this artificial sea water was taken in 500-mL Erlenmeyer flasks for the experiment. Dry sediments (NIST-1944, Standard Reference Material of particle size $120 \mu \mathrm{m}$, with area distribution) and crude oils with known quantities were added to the $500-\mathrm{mL}$ flasks that contain artificial sea water, and kept in the reciprocating shaker under $25^{\circ} \mathrm{C}$ at a constant mixing rate of $2 \mathrm{~Hz}$ (Sun et al. 2010) for a specified time interval. The flask was left undisturbed for more than $12 \mathrm{~h}$ to make sure that all the aggregates were settled at the bottom of the flask. Based on the availability, three different oils such as Arabian Light (AL), Kuwait (KW) and Murban (MB) were chosen and three different oilsediment ratios (OSRs) were tested (Supporting Information, Table S1). Initially, the experiments were carried out with $05 \mathrm{~h}$ and $10 \mathrm{~h}$ by continuous mixing. Then the experiments were repeated with the same set of fresh samples again initially for $05 \mathrm{~h}(10 \mathrm{~h})$, stopped the shaker for a couple of minutes and then added additional sediments (quantity is $200 \mathrm{mg} / \mathrm{L}$ of sediment) slowly on the top layer of the beaker without touching the walls and continued the mixing experiment for $5 \mathrm{~h}(10 \mathrm{~h})$. Thus, the total mixing time becomes $10^{*} \mathrm{~h}\left(20^{*} \mathrm{~h}\right)$. By this way, the experiments were conducted with four mixing times $05 \mathrm{~h}$, $10 \mathrm{~h}, 10^{*} \mathrm{~h}$ (05 h mixing + adding of sediments $+05 \mathrm{~h}$ mixing) and $20 * \mathrm{~h}(10 \mathrm{~h}+$ adding of sediments $+10 \mathrm{~h})$.
Khelifa et al. (2007) procedure was followed to recover the settled OSAs from the bottom of the reaction chamber. Morphology of the recovered OSAs was observed under the microscope OLYMPUS SZX2-ILLT (OLYMPUS Co, Tokyo, Japan) with DF-PLAPO- $1 \mathrm{X}_{4}$ lenses $(5 \times$ zoom). The images captured using the camera were mounted on the microscope, and measurements of the aggregates were made using the Cell Scan digital image processing software linked with the microscope camera. Reproducibility of the whole analytical procedure was checked through triplicate analysis of three samples, containing one sample from each crude oil to analyse and quantify different OSAs formed. The relative standard deviation of individual aggregate sizes were less than $12 \%$ for three samples that represent three crude oils.

\section{Extraction of aliphatic and aromatic hydrocarbons from OSAs}

Recovered OSAs were initially transferred to a separatory funnel and added $20 \mathrm{~mL}$ of dichloromethane (DCM):hexane at 1:1 ratio; the funnel was shook vigorously for $15 \mathrm{~min}$ and separated the extract in a clean conical flask. The experiment was repeated thrice, and the fourth extraction was performed only for the samples, which contain oil even after three extractions (based on visual observation). All the collected solvents were passed through the pre-weighed $0.45-\mu \mathrm{m}$ Millipore filter paper to separate the sediment particles of OSAs. The collected sediment particles were kept for dry in fume hood for $24 \mathrm{~h}$ and weighed. The total mass of sediments trapped in different OSAs was measured. The solvent sample was eventually reduced to $\approx 1.5 \mathrm{~mL}$ using rotary evaporator to perform column chromatography.

The extracted sample was transferred to $5 \%\left(\mathrm{H}_{2} \mathrm{O}\right)$ deactivated silica gel column ( $1 \mathrm{~cm}$ id $\times 9$-cm length), to remove polar compounds, and eluted all the aliphatic and aromatic hydrocarbons using $30 \mathrm{~mL}$ of DCM/hexane (1:3 ratio). Eluted sample was again reduced using rotary evaporator and transferred to fully activated silica gel column $(0.47 \mathrm{~cm}$ i.d $\times$ 18-cm length) to make two fractions (F1 and F2). The fraction F1 containing aliphatic hydrocarbons was eluted using $12 \mathrm{~mL}$ of hexane, whereas the fraction F2 containing aromatic hydrocarbons (PAHs) was eluted with $25 \mathrm{~mL}$ of DCM/hexane $(1: 3$ ratio) (Wang et al. 1994). These two fractions were reduced to near dryness under nitrogen purge, added $200 \mu \mathrm{L}$ internal standards in isooctane to make the final volume for all the samples and transferred to amber colour interlock vials for further analysis using gas chromatography-mass spectroscopy (GC-MS) (Reddy and Quinn, 1999, Wang et al.1994, Yang et al. 2014). Reproducibility of the whole analytical procedure was checked through triplicate analysis of three samples containing one sample from each crude oil to analyse and quantify different OSAs formed. Relative standard deviation of the individual n-alkane and PAHs was less than $10 \%$ and $15 \%$, respectively. 


\section{Gas chromatography-mass spectroscopy analysis}

Analyses for n-alkane and PAHs were performed on a Thermofisher Scientific Trace 1300 Gas Chromatograph coupled with Thermo TSQ8000 Mass Spectrometer with a Thermo AS 1310 auto-sampler under select ion monitoring (SIM) mode. A DB-5 column having 60 -m length $\times 0.25$-mm internal dia. with $0.25-\mu \mathrm{m}$ film thickness with helium $(1.2 \mathrm{~mL} / \mathrm{min})$ as a carrier gas was used for the sample analysis. The injector and detector temperatures were set to $260^{\circ}$ and $300{ }^{\circ} \mathrm{C}$, respectively, for n-alkane and $\mathrm{PAH}$ analyses. The oven temperature program for $\mathrm{n}$-alkane analysis was initially $50{ }^{\circ} \mathrm{C}$ hold for a minute, then ramp to $140{ }^{\circ} \mathrm{C}$ at $10^{\circ} \mathrm{C} / \mathrm{min}$, and ramp to $320^{\circ} \mathrm{C}$ at $6{ }^{\circ} \mathrm{C} / \mathrm{min}$ and finally $28 \mathrm{~min}$ hold at $320^{\circ} \mathrm{C}$. The oven temperature program for $\mathrm{PAH}$ analysis was initially $70{ }^{\circ} \mathrm{C}$ with a hold of $2 \mathrm{~min}$, ramp to $150{ }^{\circ} \mathrm{C}$ at
$30{ }^{\circ} \mathrm{C} / \mathrm{min}$ then ramp to $310{ }^{\circ} \mathrm{C}$ at $4{ }^{\circ} \mathrm{C} / \mathrm{min}$ and finally a 10 min hold at $310^{\circ} \mathrm{C}$. Typical n-alkanes and PAH chromatograms are shown in Fig. 1.

\section{Results and discussion}

\section{Morphology of OSAs}

Visual analysis on microscope imagery was performed to characterize the size and structure of the OSAs prepared in the laboratory. The results revealed that negatively buoyant OSAs formed in every mixing period. Previous studies showed that the efficiency of OSA formation was maximum when the sediment to oil ratio was closer to one (Khelifa et al. 2008, Sun et al. 2010, 2013). In the present study, we
Fig. 1 Typical n-alkanes (a, b) and PAH (c, d) chromatograms of Arabian Light crude oil (OSR $1: 1)$

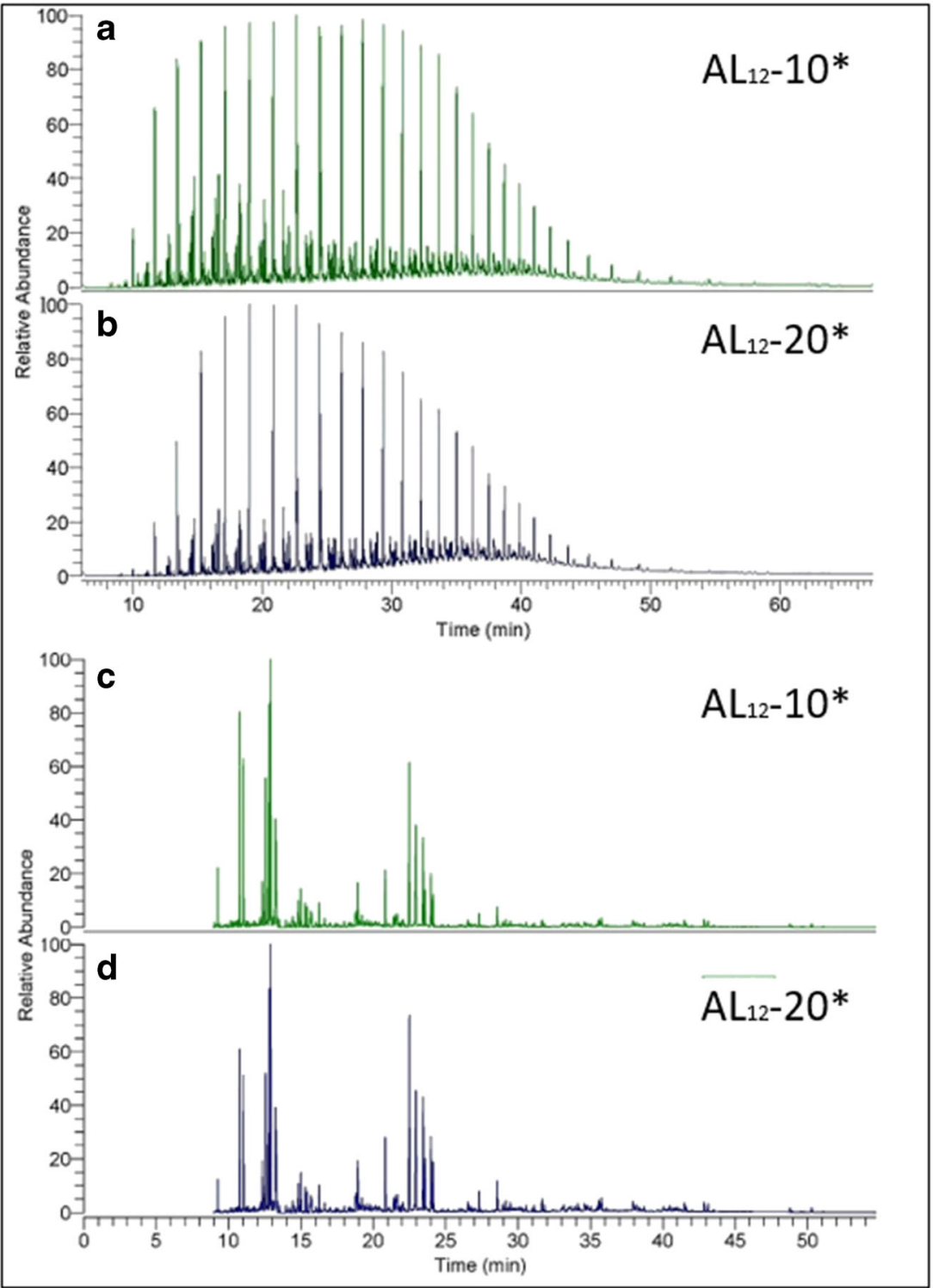


examined size and growth of the aggregates at different OSRs and weathering periods.

We found that size of the aggregates formed with the AL, $\mathrm{KW}$ and MB crude oils ranged from 0.21 to $1.66 \mathrm{~mm}, 0.26$ to $1.19 \mathrm{~mm}$ and 0.26 to $1.06 \mathrm{~mm}$, respectively (Table 1 ). The overall microscopic images of OSAs of all three crudes prepared under four mixing periods $\left(5 \mathrm{~h}, 10 \mathrm{~h}, 10^{*} \mathrm{~h}\right.$ and $20^{*} \mathrm{~h}$ ) with different OSRs are shown in Fig. 2, and also Fig. S2 and S3 in Supporting Information. It is evident from these figures that the number of aggregates formed within the first $05 \mathrm{~h}$ of continuous mixing time is apparently very less and individual sediment particles are still in the process of mixing with the oil, which commonly occurred for all the OSAs of three crudes. The number of aggregates slightly increased in 10-h continuous mixing period, but still there were sediment and oil particles still to be mixed. Small patties kind of aggregates were observed in $10^{*} \mathrm{~h}$ mixing $(5 \mathrm{~h}+$ adding of sediment + $5 \mathrm{~h})$. But only in $20^{*} \mathrm{~h}$ mixing time $(10 \mathrm{~h}+$ adding of sediment $+10 \mathrm{~h}$ ) matured aggregates were formed for all three crude oils and there were no remnant sediment particles in it.

It was very difficult to assess and count the number of aggregates from small to large size for each mixing period of respective OSR. Hence, we have discussed the processes by considering only the typical larger size aggregates (visually formed in each experiment under each OSR). The larger aggregates of sizes $1.19 \mathrm{~mm}$ and $1.06 \mathrm{~mm}$ of KW and MB crude oils were formed when the OSR is 2:2 with 20-h mixing period (sample Ids $\mathrm{KW}_{22}-20, \mathrm{MB}_{22}-20$ ). However, in the case of $\mathrm{AL}$, the larger aggregates of size $1.66 \mathrm{~mm}$ were formed within $10^{*} \mathrm{~h}$ weathering period $(5 \mathrm{~h}+$ sediment $+5 \mathrm{~h})$ when the OSR was 2:2. It may be noted that one set of experiment had been already performed with 1:1 OSR, under continuous mixing periods of $5 \mathrm{~h}$ and $10 \mathrm{~h}$, and the large aggregates of those experiments were in the ranges of $0.25-0.39 \mathrm{~mm}$ only. Hence, our results suggest that increasing the quantity of oil and sediment in equal portions (2:2) with increasing mixing period would enhance the growth of OSA's size. Though the experiments were started with OSR of 2:1, in the subsequent experiments, additional sediments were added to make the OSR 2:2, and that has significantly contributed to the growth of OSAs. Moreira et al. (2015) showed that increased sediment concentration significantly accelerated the OSA formation in the sediments of Todos Santos Bay.

The trend in the formation of small aggregates is different from that of large OSAs. The smallest aggregates with respect to $\mathrm{AL}$ and $\mathrm{MB}$ oils were $0.21 \mathrm{~mm}$ and $0.26 \mathrm{~mm}$, when the OSR was $1: 2$ and $2: 1$, respectively, under $10^{*} \mathrm{~h}$ mixing period (additional sediments were added after $5 \mathrm{~h}$ ) indicating that whenever the sediment quantity was double of oil or when the oil quantity was double of sediments, the smallest aggregates were formed. In the case of KWoil, the smallest aggregates were formed within $10 \mathrm{~h}$ of continuous mixing, but the oil and sediment quantities were in equal portions $\left(\mathrm{KW}_{22}-10\right)$. This result further suggests that the KW aggregates, which were formed by the equal amount of oil and sediment particles, might be brittle in form and were not strong enough to adsorb more SPMs. The physical properties such as viscosity and interfacial tension of $\mathrm{KW}$ may also alter the formation of aggregates.

\section{Weathering of hydrocarbons present in the OSAs}

\section{Distribution of $\mathbf{n}$-alkanes}

The compounds n-alkane and PAHs have been widely used in oil spill forensic studies, primarily to evaluate and quantify the weathering of different OSA samples. The total concentrations of $n$-alkanes from $n-C_{8}$ to $n-C_{40}$, including individual
Table 1 Typical size of the oil sediment aggregates for all the samples (AL, KW and MB are Arabian Light, Kuwait and Murban crude oils; subscript numbers represents oil sediment ratios)

\begin{tabular}{|c|c|c|c|c|c|}
\hline Sample ID & $\begin{array}{l}\text { Max. size of } \\
\text { OSA's }(\mathrm{mm})\end{array}$ & Sample ID & $\begin{array}{l}\text { Max. size of } \\
\text { OSAs (mm) }\end{array}$ & Sample ID & $\begin{array}{l}\text { Max. size of } \\
\text { OSAs (mm) }\end{array}$ \\
\hline $\mathrm{AL}_{11}-05$ & 0.25 & $\mathrm{KW}_{11}-05$ & 0.28 & $\mathrm{MB}_{11}-05$ & 0.29 \\
\hline $\mathrm{AL}_{11}-10$ & 0.32 & $\mathrm{KW}_{11}-10$ & 0.26 & $\mathrm{MB}_{11}-10$ & 0.39 \\
\hline $\mathrm{AL}_{12}-10^{*}$ & 0.21 & $\mathrm{KW}_{12}-10^{*}$ & 0.53 & $\mathrm{MB}_{12}-10^{*}$ & 0.36 \\
\hline $\mathrm{AL}_{12}-20^{*}$ & 1.25 & $\mathrm{KW}_{12}-20^{*}$ & 0.73 & $\mathrm{MB}_{12}-20^{*}$ & 0.98 \\
\hline $\mathrm{AL}_{12}-05$ & 0.30 & $\mathrm{KW}_{12^{2}-05}$ & 0.32 & $\mathrm{MB}_{12}-05$ & 0.34 \\
\hline $\mathrm{AL}_{12}-10$ & 0.28 & $\mathrm{KW}_{12^{2}}-10$ & 0.39 & $\mathrm{MB}_{12}-10$ & 0.29 \\
\hline $\mathrm{AL}_{13}-10^{*}$ & 1.25 & $\mathrm{KW}_{13}-10^{*}$ & 0.31 & $\mathrm{MB}_{13}-10^{*}$ & 0.36 \\
\hline $\mathrm{AL}_{13}-20^{*}$ & 0.39 & $\mathrm{KW}_{13}-20^{*}$ & 0.61 & $\mathrm{MB}_{13}-20^{*}$ & 0.35 \\
\hline $\mathrm{AL}_{21}-05$ & 0.25 & $\mathrm{KW}_{21}-05$ & 0.33 & $\mathrm{MB}_{21}-05$ & 0.27 \\
\hline $\mathrm{AL}_{21}-10$ & 0.33 & $\mathrm{KW}_{21}-10$ & 0.28 & $\mathrm{MB}_{21}-10$ & 0.26 \\
\hline $\mathrm{AL}_{22}-10^{*}$ & 1.66 & $\mathrm{KW}_{22}-10^{*}$ & 0.66 & $\mathrm{MB}_{22^{2}}-10^{*}$ & 0.35 \\
\hline $\mathrm{AL}_{22}-20^{*}$ & 0.26 & $\mathrm{KW}_{22}-20^{*}$ & 1.19 & $\mathrm{MB}_{22}-20^{*}$ & 1.06 \\
\hline
\end{tabular}

-05: 05 h continuous mixing

-10: $10 \mathrm{~h}$ continuous mixing

$-10^{*}: 5 \mathrm{~h}$ mixing + adding of sediments $+5 \mathrm{~h}$ mixing

$-20^{*}: 10 \mathrm{~h}$ mixing + adding of sediments $+10 \mathrm{~h}$ mixing 

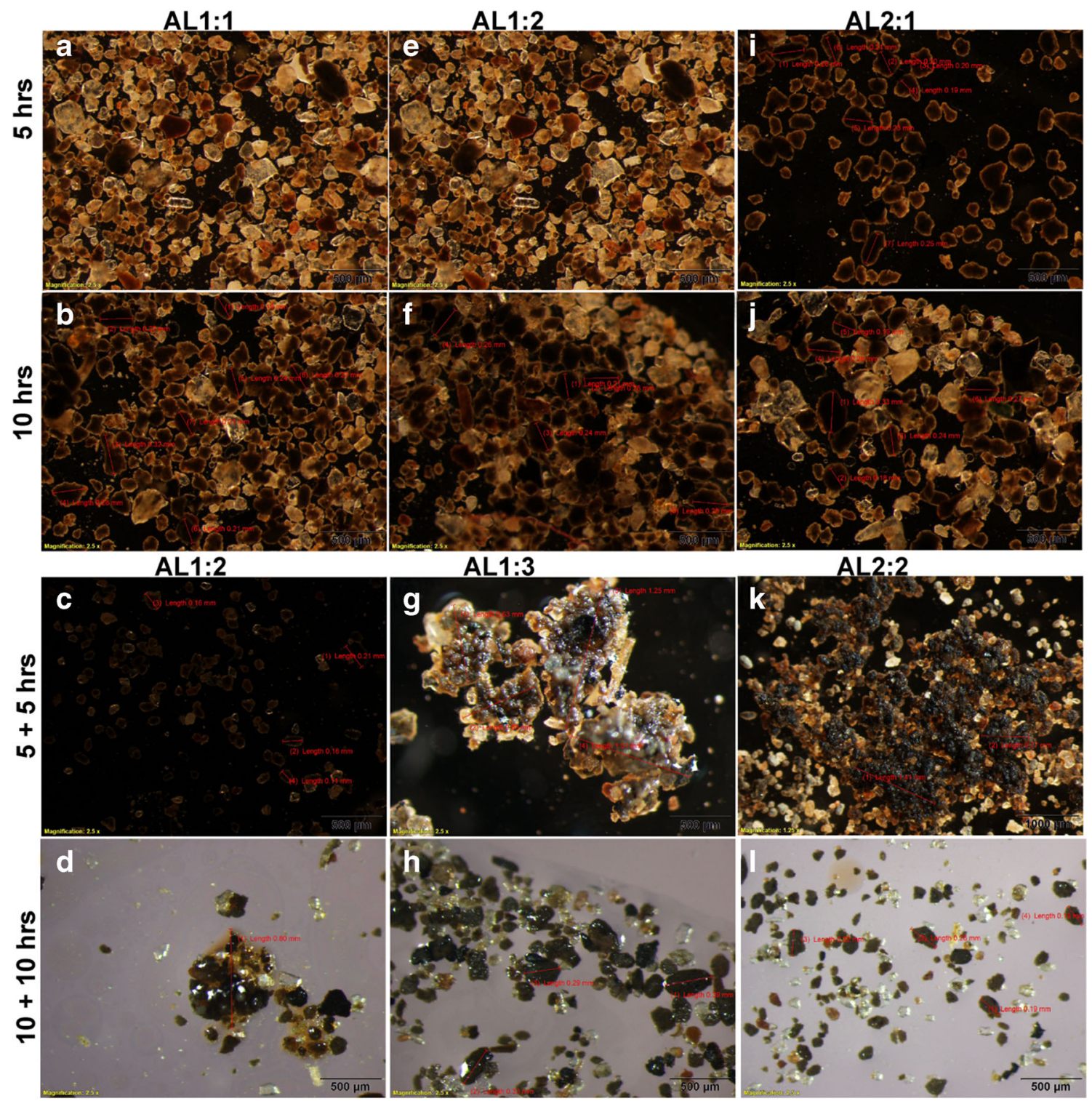

Fig. 2 Typical view of microscopic images of AL OSAs under different mixing times and OSRs

isoprenoid hydrocarbons, pristane $(\mathrm{Pr})$ and phytane $(\mathrm{Ph})$ of all 36 OSA samples and their diagnostic ratios used for weathering are also shown in Table 2 and Figs. 3, 4 and 5.

It is apparent that the depletion of total $n$-alkanes was highest for all the 10-h continuous mixing samples (weathered without additional sediments), irrespective of OSR and type of oils (pink bars in Figs. 3, 4 and 5). The diagnostic ratios (DRs) of n-alkanes such as percentage depletion, and Weathering Index $\left(\mathrm{WI}-\left(\mathrm{C}_{8}+\mathrm{C}_{10}+\mathrm{C}_{12}+\mathrm{C}_{14}\right) /\left(\mathrm{C}_{22}+\mathrm{C}_{24}+\mathrm{C}_{26}+\mathrm{C}_{28}\right)\right.$ ) and $\left(\mathrm{C}_{13}+\mathrm{C}_{14}\right) /\left(\mathrm{C}_{25}+\mathrm{C}_{26}\right)$, were used to assess weathering and its extent for any hydrocarbon pollutants (Zakaria et al. 2001, Suneel et al. 2013, 2014, 2015). The DR $\left(C_{13}+C_{14}\right) /$ $\left(\mathrm{C}_{25}+\mathrm{C}_{26}\right)$ was previously used by Yim et al. (2011). Based on the range of this ratio, Ho et al. (2015) categorized the status of oil weathering into four stages such as initial weathering (ratio $>1$ ), moderate weathering (ratio between
0.1 and 1.0), advanced weathering (ratio between 0.01 and 0.1 ) and extreme weathering (ratio $<0.01)$. In the present study, the calculated ratio of $\left(\mathrm{C}_{13}+\mathrm{C}_{14}\right) /\left(\mathrm{C}_{25}+\mathrm{C}_{26}\right)$ was greater than 1 for all OSAs except two samples 211-01 $(0.20)$ and 221-01 (0.31), revealing that the samples have undergone initial weathering.

The ratio WI was used to assess weathering of low and high molecular weight compounds - the lower the ratio, the greater the weathering (Wang et al. 1994, Suneel et al. 2015). The values of WI for $\mathrm{AL}, \mathrm{KW}$ and MB were 1.02, 1.24 and 1.06, respectively, revealing that no weathering has occurred (as WI $\sim 1)$. The value of this ratio would be higher if the lower alkanes were abundant and lower if the higher n-alkanes were abundant. This value ranged from 0.39 to $0.91,0.06$ to 1.12 and 0.4 to 0.95 , respectively, for the aggregates prepared with various OSRs of $\mathrm{AL}, \mathrm{KW}$ and $\mathrm{MB}$ crude oils, showing 
Table 2 Diagnostic ratios of n-alkanes

\begin{tabular}{|c|c|c|c|c|}
\hline Sample ID & $\Sigma$ n-alkanes $(\mu \mathrm{g} / \mathrm{g}$ of OSAs) & WI & $\%$ weathered n-alkanes & $\left(\mathrm{C}_{13}+\mathrm{C}_{14}\right) /\left(\mathrm{C}_{25}+\mathrm{C}_{26}\right)$ \\
\hline $\mathrm{AL}$ & $223,087.00$ & 1.02 & - & 1.87 \\
\hline KW & $164,812.00$ & 1.24 & - & 2.43 \\
\hline MB & $179,379.00$ & 1.06 & - & 1.93 \\
\hline $\mathrm{AL}_{11}-05$ & $120,342.00$ & 0.39 & 46.06 & 1.31 \\
\hline $\mathrm{AL}_{11}-10$ & $34,494.00$ & 0.45 & 84.54 & 1.51 \\
\hline $\mathrm{AL}_{12}-10^{*}$ & $148,594.00$ & 0.88 & 33.39 & 1.99 \\
\hline $\mathrm{AL}_{12}-20^{*}$ & $95,897.00$ & 0.74 & 57.01 & 1.98 \\
\hline $\mathrm{AL}_{12}-05$ & $183,213.00$ & 0.62 & 17.87 & 1.65 \\
\hline $\mathrm{AL}_{12}-10$ & $47,304.00$ & 0.72 & 78.80 & 1.83 \\
\hline $\mathrm{AL}_{13}-10^{*}$ & $97,747.00$ & 0.88 & 56.18 & 2.01 \\
\hline $\mathrm{AL}_{13}-20^{*}$ & $65,704.00$ & 0.85 & 70.55 & 2.13 \\
\hline $\mathrm{AL}_{21}-05$ & $96,824.00$ & 0.71 & 56.59 & 1.77 \\
\hline $\mathrm{AL}_{21}-10$ & $85,188.00$ & 0.56 & 61.81 & 1.53 \\
\hline $\mathrm{AL}_{22}-10^{*}$ & $172,767.00$ & 0.91 & 22.56 & 1.95 \\
\hline $\mathrm{AL}_{22}-20^{*}$ & $106,912.00$ & 0.88 & 52.08 & 2.12 \\
\hline $\mathrm{KW}_{11}-05$ & $35,737.00$ & 0.06 & 78.32 & 0.20 \\
\hline $\mathrm{KW}_{11}-10$ & $29,256.00$ & 0.26 & 82.25 & 1.06 \\
\hline $\mathrm{KW}_{12}-10^{*}$ & $36,369.00$ & 0.55 & 77.93 & 1.72 \\
\hline $\mathrm{KW}_{12}-20^{*}$ & $55,254.00$ & 0.87 & 66.47 & 2.27 \\
\hline $\mathrm{KW}_{12}-05$ & $50,868.00$ & 0.55 & 69.14 & 1.85 \\
\hline $\mathrm{KW}_{12}-10$ & 9584.70 & 0.44 & 94.18 & 1.49 \\
\hline $\mathrm{KW}_{13}-10^{*}$ & $35,203.00$ & 0.54 & 78.64 & 1.55 \\
\hline $\mathrm{KW}_{13}-20^{*}$ & $41,815.00$ & 0.94 & 74.63 & 2.31 \\
\hline $\mathrm{KW}_{21}-05$ & $48,823.00$ & 0.10 & 70.38 & 0.31 \\
\hline $\mathrm{KW}_{21}-10$ & $22,552.00$ & 0.37 & 86.32 & 1.35 \\
\hline $\mathrm{KW}_{22}-10^{*}$ & $112,549.00$ & 1.12 & 31.71 & 2.75 \\
\hline $\mathrm{KW}_{22}-20^{*}$ & $98,952.00$ & 1.03 & 39.96 & 2.51 \\
\hline $\mathrm{MB}_{11}-05$ & $90,821.00$ & 0.40 & 49.37 & 1.22 \\
\hline $\mathrm{MB}_{11}-10$ & $46,330.00$ & 0.70 & 74.17 & 2.28 \\
\hline $\mathrm{MB}_{12}-10^{*}$ & $50,451.00$ & 0.71 & 71.87 & 1.85 \\
\hline $\mathrm{MB}_{12}-20^{*}$ & $64,662.00$ & 0.76 & 63.95 & 1.81 \\
\hline $\mathrm{MB}_{12}-05$ & $46,939.00$ & 0.48 & 73.83 & 1.56 \\
\hline $\mathrm{MB}_{12}-10$ & $35,896.00$ & 0.67 & 79.99 & 2.02 \\
\hline $\mathrm{MB}_{13}-10^{*}$ & $27,792.00$ & 0.62 & 84.51 & 1.67 \\
\hline $\mathrm{MB}_{13}-20^{*}$ & $76,637.00$ & 0.81 & 57.28 & 1.95 \\
\hline $\mathrm{MB}_{21}-05$ & $89,895.00$ & 0.41 & 49.89 & 1.31 \\
\hline $\mathrm{MB}_{21}-10$ & $28,950.00$ & 0.37 & 83.86 & 1.26 \\
\hline $\mathrm{MB}_{22}-10^{*}$ & $86,990.00$ & 0.95 & 51.50 & 2.19 \\
\hline $\mathrm{MB}_{22}-20^{*}$ & $74,265.00$ & 0.79 & 58.60 & 1.70 \\
\hline
\end{tabular}

$\mathrm{WI}=\frac{(\mathbf{C} 8+\mathbf{C 1 0}}{+\mathbf{C 1 2}+\mathbf{C 1 4})}$

reduction in WI compared to their reference oils. This indicates depletion of LMW components compared to HMW.

Figure 6 depicts the temporal change in WI of n-alkanes for all the aggregates. The $\mathrm{WI}$ of $\mathrm{AL}$ and $\mathrm{MB}$ (blue and green lines) aggregates exhibits a similar trend, whereas KW aggregates have shown a slight difference. As discussed in the previous section, the distribution of KW crude OSAs has also shown a slight difference compared to other two crudes. Surprisingly, the highest WI or maximum depletion of LMW compounds has occurred for all the three crude aggregates 

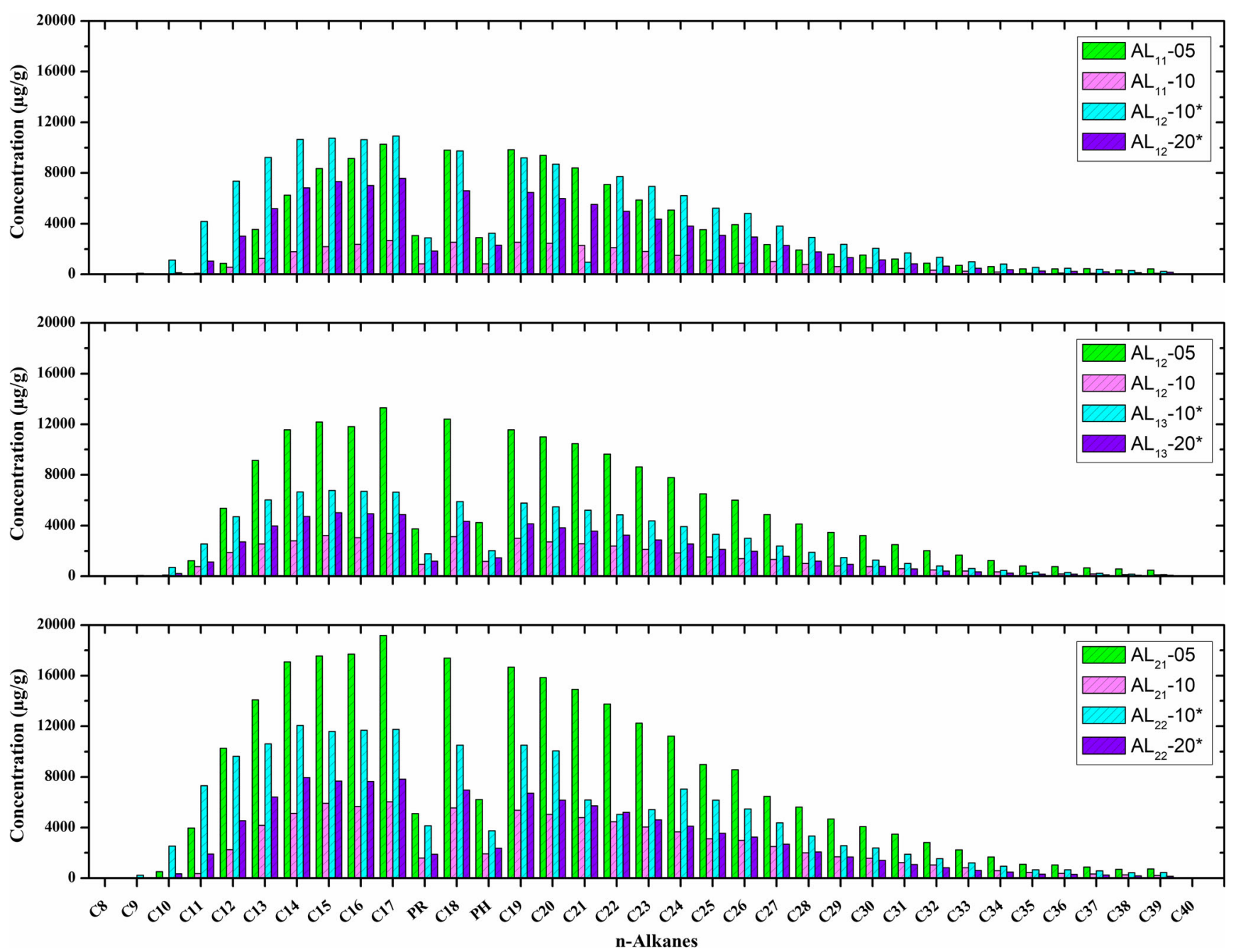

Fig. 3 Distribution of n-alkanes in AL OSA samples

rapidly within the first $05 \mathrm{~h}$ mixing time whenever the quantity of sediment was equal to oil (1:1_05) or less than the oil $(2: 105)$. The temporal variation of WI is in the order of $05 \bar{h}>10 h>10 h^{*}>20 h^{*}$. Now the question is how the less mixing time $(5 \mathrm{~h})$ caused high WI and high mixing time $(20 \mathrm{~h})$ caused less WI. It is evident from Fig. 2 that 05 -h mixing may not be adequate for the formation of aggregates as the oil that was added to the system has not completely utilized to form the aggregates (only less aggregates were formed in 5-h mixing time). Only a partial quantity of oil and sediments were being used and the rest of the particles persisted in the water. When the mixing time was increased or additional sediments were added, the already-partially-formed aggregates adsorbed the remaining oil and the sediment particles that were still persisted in the system (beaker). Thus, hydrocarbons persisted in the water get back to the aggregates resulting in increase of concentration.
It is evident from Fig. 2 that only at 20-h mixing period, matured aggregates were formed and the system was apparently clean as there seemed to be no individual oil and sediment residuals in the beaker, further indicating that all the oil and sediment particles might have been completely used for the formation of OSAs. Therefore, as long as hydrocarbons persisted in the system (beaker), they must have been absorbed by the aggregates during their residing time. Thus, less weathering was showed on the aggregates while mixing time increased from 5 to $20 \mathrm{~h}$. Therefore, all the aggregates have shown less weathering consistently.

The total mass of n-alkanes and PAHs that were weathered in different OSR ratios indifferent weathering experiments was calculated using the following formula

Actual $\%$ depletion of $\mathrm{n}$-alkanes $/ \mathrm{PAHs}=\left(1-\frac{m_{\text {weathered }}}{m_{\text {source oil }}}\right) \times 100$ 

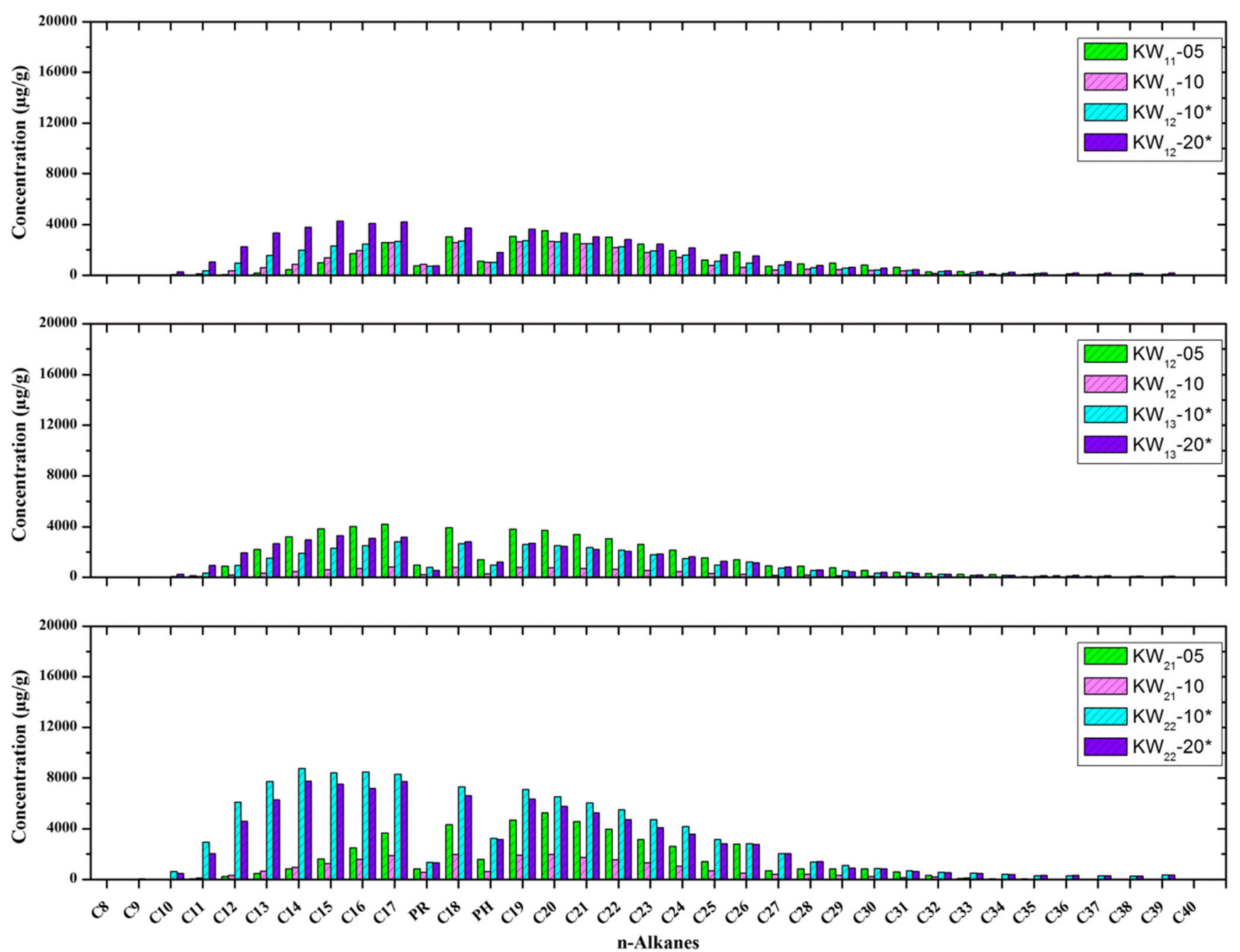

Fig. 4 Distribution of n-alkanes in KW OSAs

where $m_{\text {weathered }}$ is the total mass of n-alkanes remained in OSAs after weathering, and $m_{\text {sourceoil }}$ is the total mass of nalkanes present in the respective source crude oils. The total nalkanes present in the source oils $\mathrm{AL}, \mathrm{KW}$ and $\mathrm{MB}$ were $223,087 \mu \mathrm{g} / \mathrm{g}, 164,812 \mu \mathrm{g} / \mathrm{g}$ and $179,379 \mu \mathrm{g} / \mathrm{g}$, respectively, indicating that $\mathrm{AL}$ is relatively abundant in n-alkanes than in the other two crudes. The results revealed that the rate of depletion differed for each type of crude oil (Fig. 10). As depicted in Fig. 10, 10-h continuous mixing and $20^{*} \mathrm{~h}$ mixing samples were highly weathered than 05 -h continuous mixing and $10^{*} \mathrm{~h}$ mixing samples, probably due to the long mixing periods (Table S1:10h, $20 \mathrm{~h}$ ). The maximum depletion percentage was $84 \%\left(\mathrm{AL}_{11}-10\right), 94 \%\left(\mathrm{KW}_{12}-10\right)$ and $84 \%$ $\left(\mathrm{MB}_{21}-10\right)$ for $\mathrm{AL}, \mathrm{KW}$ and $\mathrm{MB}$ crude oil, respectively, showing that the highest weathering has occurred only at 10-h continuous mixing samples. In general, all the 10-h continuous mixing samples showed the highest percentage of weathering compared to other mixing time samples. In case of AL OSA samples, samples of $10^{*} \mathrm{~h}$ mixing were less weathered (approx. 20-25\%) compared with 20\% hixing samples.
However, a few $10^{*} \mathrm{~h}$ mixing OSAs of $\mathrm{KW}$ and MB have weathered $(10 \%, 4 \%$ and $7.92 \%$ and $27.23 \%$ ) higher than $20 \mathrm{~h}$ mixing. The reason for higher weathering rates could be the interaction between oil and sediments, and also the type of oil and their physical properties (e.g. viscosity, interfacial tension). A detailed study is required to understand these physicochemical processes thoroughly which is beyond the scope of the present study.

\section{Weathering of polycyclic aromatic hydrocarbons}

In this study, a total of $33 \mathrm{PAH}$ compounds (parent and alkylated PAHs, Table S2, in Supporting Information) were quantified in all the OSAs and reference crude oils in order to study the distribution of PAHs under different weathering periods. The list of PAH compounds are given in Table S2 and their diagnostic ratios in Table 3 .

The results show that total PAH abundance was 6257, 4117 and $6488 \mu \mathrm{g} / \mathrm{g}$, respectively, for AL, KW and MB crude oils, whereas the concentration in their respective OSAs varied 

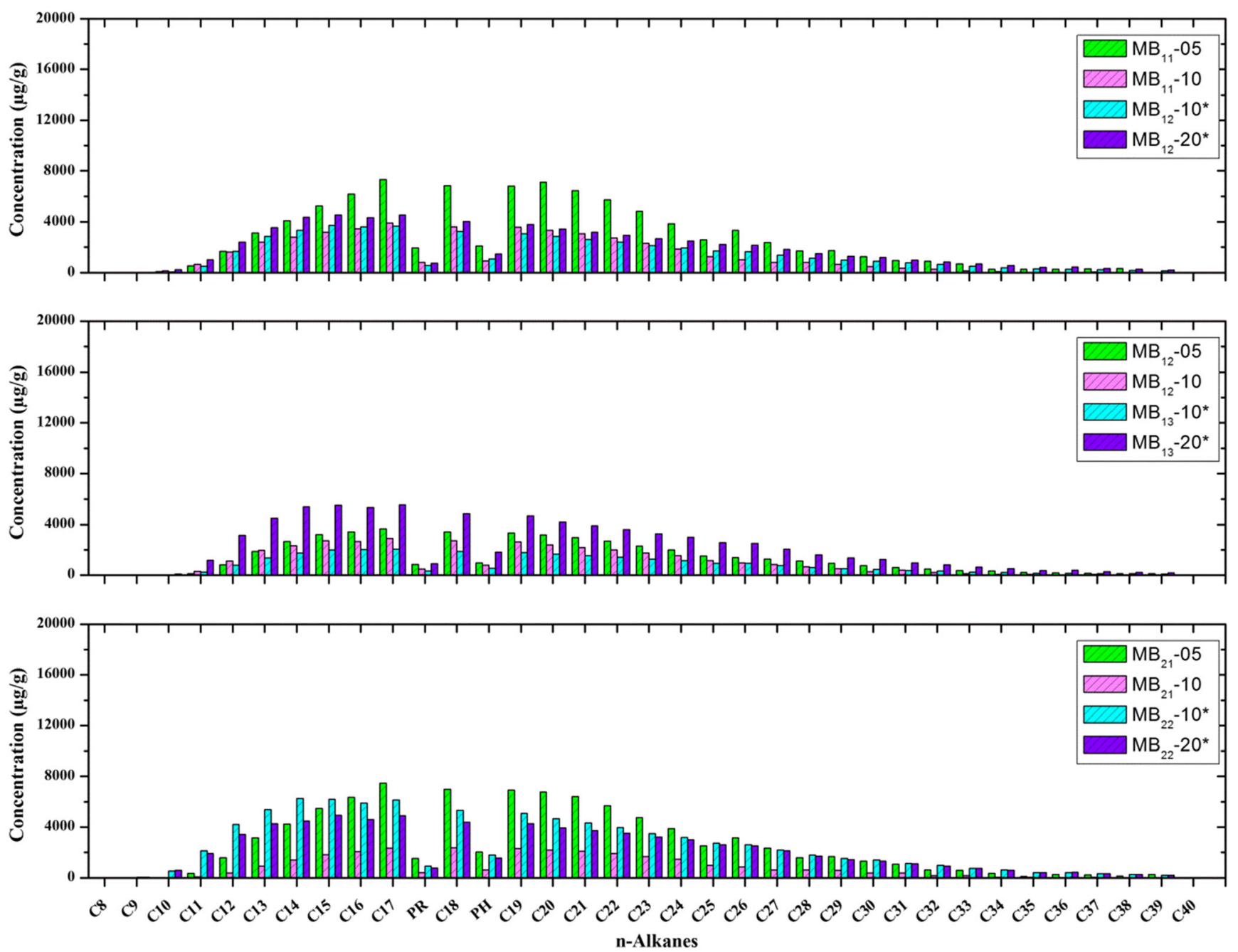

Fig. 5 Distribution of n-alkanes in MB OSAs

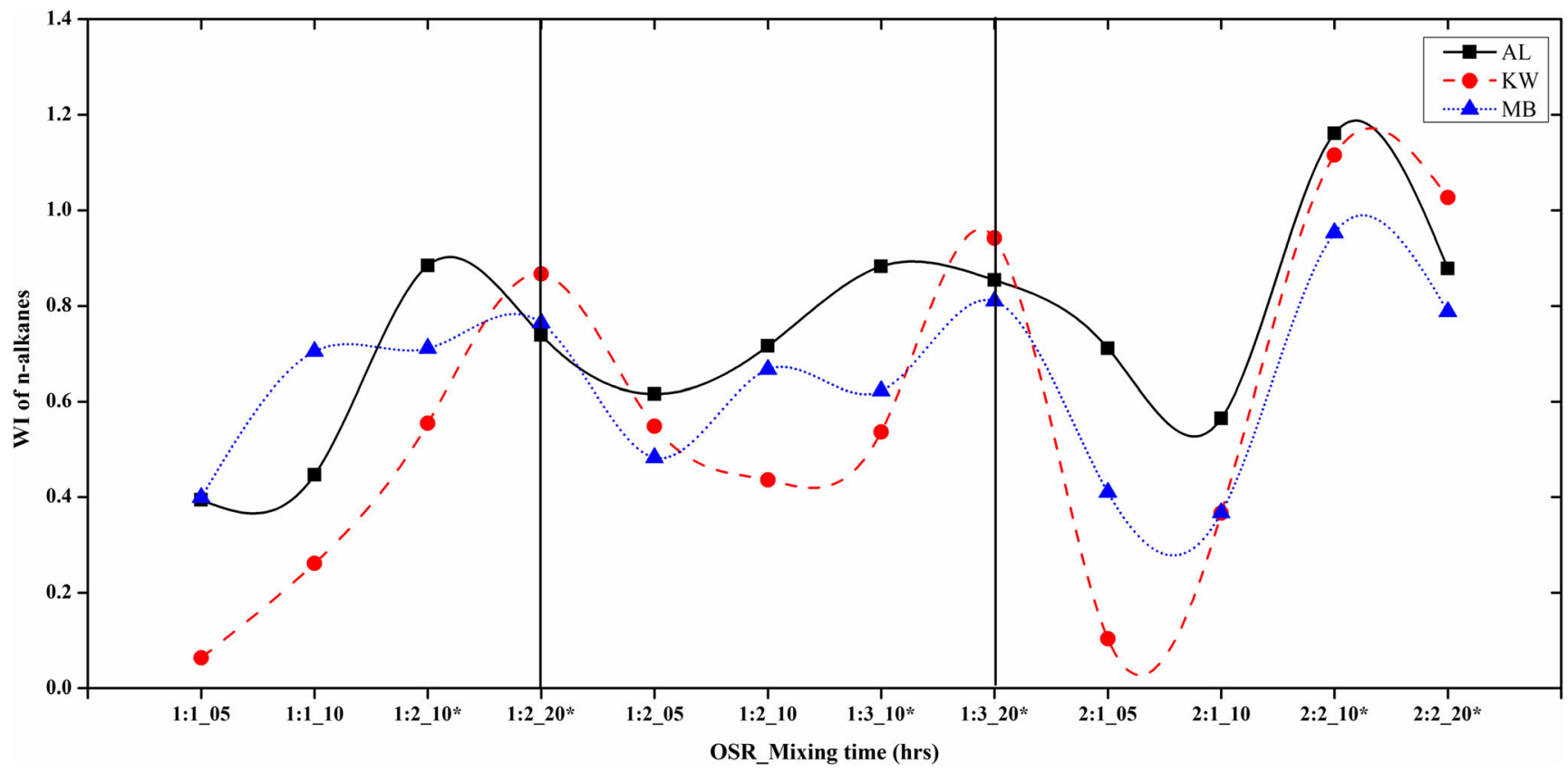

Fig. 6 Temporal changes of WI of n-alkanes 
Table 3 Total PAH's and their diagnostic ratio's

\begin{tabular}{|c|c|c|c|c|c|c|c|c|}
\hline Sample ID & $\Sigma \mathrm{PAH}(\mu \mathrm{g} / \mathrm{g})$ & $\%$ depletion of PAHs & LMW & HMW & $\mathrm{L} / \mathrm{H}$ & $\mathrm{MP} / \mathrm{P}$ & $\mathrm{PH} / \mathrm{AN}$ & FLU/PY \\
\hline $\mathrm{AL}$ & 6257.02 & - & 1498.02 & 191.31 & 7.83 & 2.99 & 62.08 & 0.12 \\
\hline KW & 4117.00 & - & 635.53 & 161.41 & 3.94 & 2.89 & 78.36 & 0.15 \\
\hline MB & 6488.05 & - & 773.29 & 277.94 & 2.78 & 3.05 & 69.97 & 0.07 \\
\hline $\mathrm{AL}_{11}-05$ & 2101.00 & 66.42 & 144.75 & 575.75 & 0.25 & 2.36 & 19.30 & 0.70 \\
\hline $\mathrm{AL}_{11}-10$ & 1752.50 & 71.99 & 172.28 & 458.66 & 0.38 & 2.46 & 13.86 & 0.62 \\
\hline $\mathrm{AL}_{12}-10^{*}$ & 4170.00 & 33.35 & 526.78 & 606.33 & 0.87 & 2.66 & 35.58 & 0.68 \\
\hline $\mathrm{AL}_{12}-20^{*}$ & 2949.90 & 52.85 & 226.97 & 469.42 & 0.48 & 2.93 & 24.94 & 0.64 \\
\hline $\mathrm{AL}_{12}-05$ & 3380.40 & 45.97 & 320.88 & 676.98 & 0.47 & 2.63 & 27.97 & 0.70 \\
\hline $\mathrm{AL}_{12}-10$ & 2316.20 & 62.98 & 223.31 & 456.40 & 0.49 & 2.70 & 24.22 & 0.62 \\
\hline $\mathrm{AL}_{13}-10^{*}$ & 3376.50 & 46.04 & 365.93 & 768.25 & 0.48 & 2.59 & 24.34 & 0.75 \\
\hline $\mathrm{AL}_{13}-20^{*}$ & 2149.70 & 65.64 & 188.31 & 374.01 & 0.50 & 2.73 & 28.80 & 0.67 \\
\hline $\mathrm{AL}_{21}-05$ & 4099.20 & 34.49 & 290.17 & 527.46 & 0.55 & 2.80 & 32.55 & 0.52 \\
\hline $\mathrm{AL}_{21}-10$ & 2401.70 & 61.62 & 138.92 & 313.53 & 0.44 & 2.83 & 39.98 & 0.52 \\
\hline $\mathrm{AL}_{22}-10^{*}$ & 5398.00 & 13.73 & 691.85 & 575.86 & 1.20 & 2.69 & 37.78 & 0.51 \\
\hline $\mathrm{AL}_{22}-20^{*}$ & 3902.40 & 37.63 & 201.28 & 567.64 & 0.35 & 2.83 & 35.34 & 0.57 \\
\hline $\mathrm{KW}_{11}-05$ & 1090.20 & 73.52 & 108.47 & 439.99 & 0.25 & 2.01 & 10.76 & 0.73 \\
\hline $\mathrm{KW}_{11}-10$ & 1050.70 & 74.48 & 79.95 & 313.57 & 0.26 & 2.24 & 8.41 & 0.59 \\
\hline $\mathrm{KW}_{12}-10^{*}$ & 1745.10 & 57.61 & 170.43 & 599.47 & 0.28 & 2.16 & 12.27 & 0.71 \\
\hline $\mathrm{KW}_{12}-20^{*}$ & 2137.10 & 48.09 & 157.91 & 535.09 & 0.30 & 2.52 & 21.42 & 0.74 \\
\hline $\mathrm{KW}_{12}-05$ & 1504.60 & 63.45 & 144.62 & 430.21 & 0.34 & 2.08 & 14.99 & 0.73 \\
\hline $\mathrm{KW}_{12}-10$ & 849.87 & 79.36 & 80.75 & 413.96 & 0.20 & 1.93 & 8.56 & 0.80 \\
\hline $\mathrm{KW}_{13}-10^{*}$ & 2335.30 & 43.28 & 251.55 & 983.54 & 0.26 & 1.89 & 9.19 & 0.83 \\
\hline $\mathrm{KW}_{13}-20^{*}$ & 2023.30 & 50.85 & 169.96 & 497.38 & 0.34 & 2.55 & 18.95 & 0.75 \\
\hline $\mathrm{KW}_{21}-05$ & 1250.20 & 69.63 & 133.31 & 409.38 & 0.33 & 2.24 & 9.71 & 0.69 \\
\hline $\mathrm{KW}_{21}-10$ & 1561.70 & 62.07 & 145.55 & 564.31 & 0.26 & 2.17 & 9.57 & 0.74 \\
\hline $\mathrm{KW}_{22}-10^{*}$ & 3674.50 & 10.75 & 371.84 & 671.06 & 0.55 & 2.62 & 24.82 & 0.74 \\
\hline $\mathrm{KW}_{22}-20^{*}$ & 4084.70 & 0.78 & 384.19 & 717.83 & 0.54 & 2.79 & 25.26 & 0.66 \\
\hline $\mathrm{MB}_{11^{-05}}$ & 2177.20 & 66.44 & 160.86 & 350.72 & 0.46 & 2.54 & 21.17 & 0.56 \\
\hline $\mathrm{MB}_{11}-10$ & 3383.90 & 47.84 & 300.58 & 583.62 & 0.52 & 2.52 & 18.47 & 0.55 \\
\hline $\mathrm{MB}_{12}-10^{*}$ & 1218.90 & 72.96 & 71.85 & 214.69 & 0.33 & 2.70 & 32.01 & 0.65 \\
\hline $\mathrm{MB}_{12}-20^{*}$ & 1922.10 & 70.37 & 110.42 & 373.77 & 0.30 & 2.73 & 30.66 & 0.64 \\
\hline $\mathrm{MB}_{12}-05$ & 1553.10 & 76.06 & 165.21 & 431.61 & 0.38 & 2.24 & 17.25 & 0.73 \\
\hline $\mathrm{MB}_{12}-10$ & 1754.20 & 81.21 & 111.78 & 369.50 & 0.30 & 2.61 & 22.52 & 0.63 \\
\hline $\mathrm{MB}_{13}-10^{*}$ & 1411.30 & 78.25 & 130.17 & 501.23 & 0.26 & 2.30 & 15.28 & 0.78 \\
\hline $\mathrm{MB}_{13}-20^{*}$ & 3036.10 & 53.20 & 187.72 & 598.93 & 0.31 & 2.69 & 28.29 & 0.66 \\
\hline $\mathrm{MB}_{21}-05$ & 2965.20 & 54.30 & 266.13 & 615.99 & 0.43 & 2.38 & 14.29 & 0.60 \\
\hline $\mathrm{MB}_{21}-10$ & 1633.10 & 74.83 & 98.94 & 441.12 & 0.22 & 2.44 & 15.41 & 0.58 \\
\hline $\mathrm{MB}_{22}-10^{*}$ & 1855.70 & 71.40 & 159.07 & 245.66 & 0.65 & 2.87 & 39.99 & 0.54 \\
\hline $\mathrm{MB}_{22}-20^{*}$ & 3780.40 & 41.73 & 474.28 & 478.33 & 0.99 & 2.89 & 37.27 & 0.54 \\
\hline
\end{tabular}

LMW: sum of naphthalene, acenaphthylene, acenaphthene, fluorene, phenanthrene and anthracene

HMW: sum of fluoranthene, pyrene, benz(a)anthracene, chrysene, benzo[b]fluoranthene, benzo[k]fluoranthene, benzo[a]pyrene, benzo[g,h,i]perylene dibenz[a,h]anthracene, indeno[1,2,3-c,d]pyrene

MP/P: sum of 3-methylephenanthrene + 2-methylephenanthrene + 9-methylephenanthrene + 1-methylephenanthrene relative to phenanthrene

Actual $\%$ depletion of n-alkanes/PAHs $=\left(1-\frac{m_{\text {weathered }}}{m_{\text {sourceoil }}}\right) \times 100 ; m_{\text {weathered }}$ is the total mass of n-alkanes remained in OSAs after weathering, $m_{\text {source oil }}$ is the total mass of n-alkanes present in the respective source crude oils

from $1752.5 \mu \mathrm{g} / \mathrm{g}\left(\mathrm{AL}_{11}-10\right)$ to $5398 \mu \mathrm{g} / \mathrm{g}\left(\mathrm{AL}_{22}-20^{*}\right)$, $849.87 \mu \mathrm{g} / \mathrm{g}\left(\mathrm{KW}_{12}-10\right)$ to $4084.7 \mu \mathrm{g} / \mathrm{g}\left(\mathrm{KW}_{22}-20^{*}\right)$ and $1218.9 \mu \mathrm{g} / \mathrm{g}\left(\mathrm{MB}_{11}-10^{*}\right)$ to $3780.4 \mu \mathrm{g} / \mathrm{g}$ (321-04), respectively.

The PAH profiles of OSAs prepared with AL, KW and MB crudes are shown in Figs. 7, 8 and 9, respectively. As shown in the figures, all three crude oils contain very less or completely absent $1 \mathrm{MA}$ and $5 \mathrm{MCH}$, whereas high concentration of phenanthrene in all three crude aggregates. Figure 7 shows the PAH profiles of OSAs prepared with the AL oil. The compounds phenanthrene, methyl phenanthrenes, naphthalene, fluoranthene and pyrene were present more abundant than other PAHs indicating that these compounds were less weathered. All other PAHs have equally depleted.

The maximum depletion occurred in most of the PAH compounds at $10-\mathrm{h}$ continuous mixing period in all combinations $\left(\mathrm{AL}_{11}-10, \mathrm{AL}_{12}-10, \mathrm{AL}_{21}-10\right)$ which indicates that irrespective of quantity of sediment and oil, these compounds have depleted with respect to time within the first $10 \mathrm{~h}$. A similar trend was also observed 

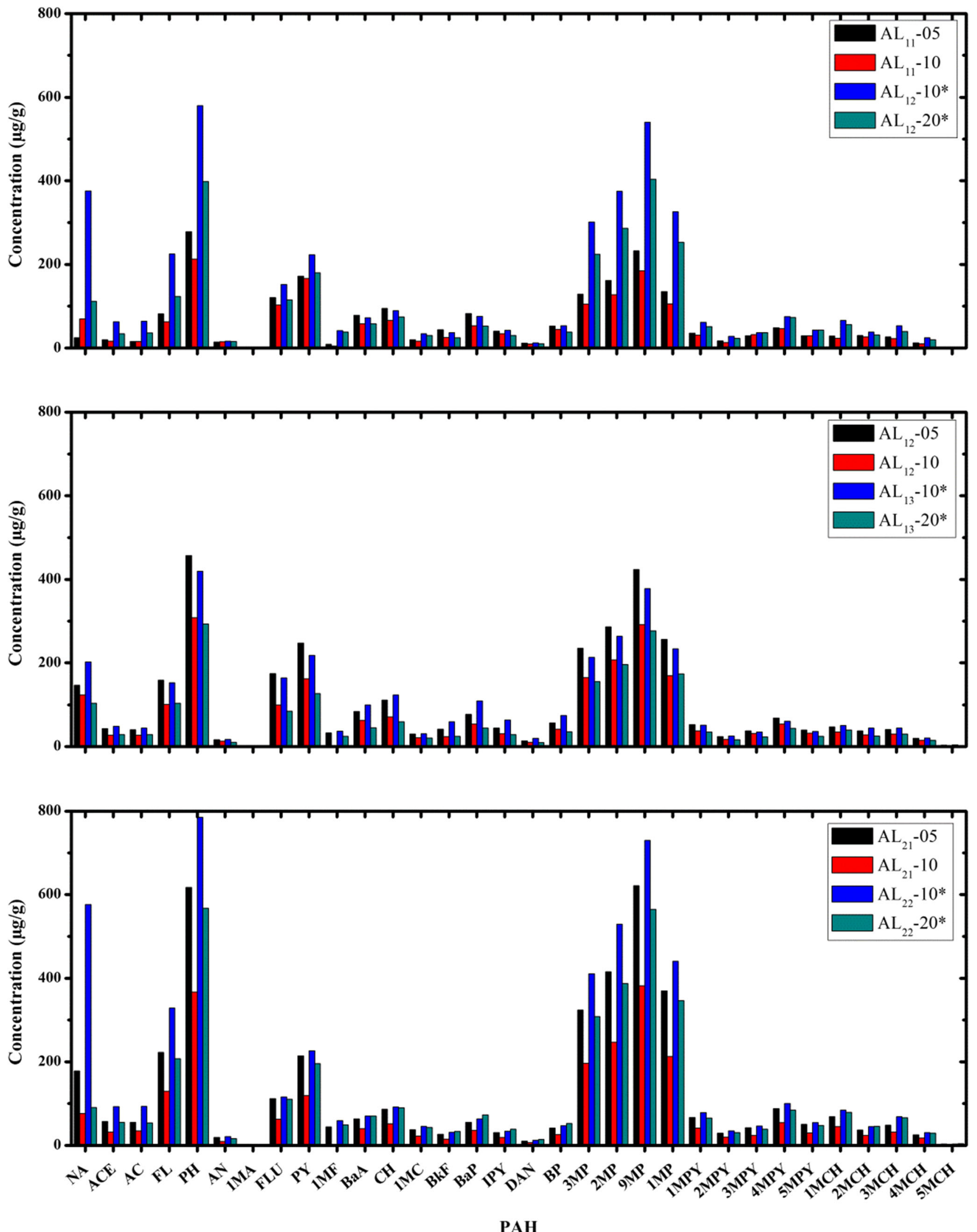

Fig. 7 Concentration of PAHs in AL OSAs (the abbreviations are given in Table S2, in Supporting Information) 
Fig. 8 Weathering percentage of n-alkanes and PAHs at constant OSR with continuous mixing and mixing with addition of sediment in between

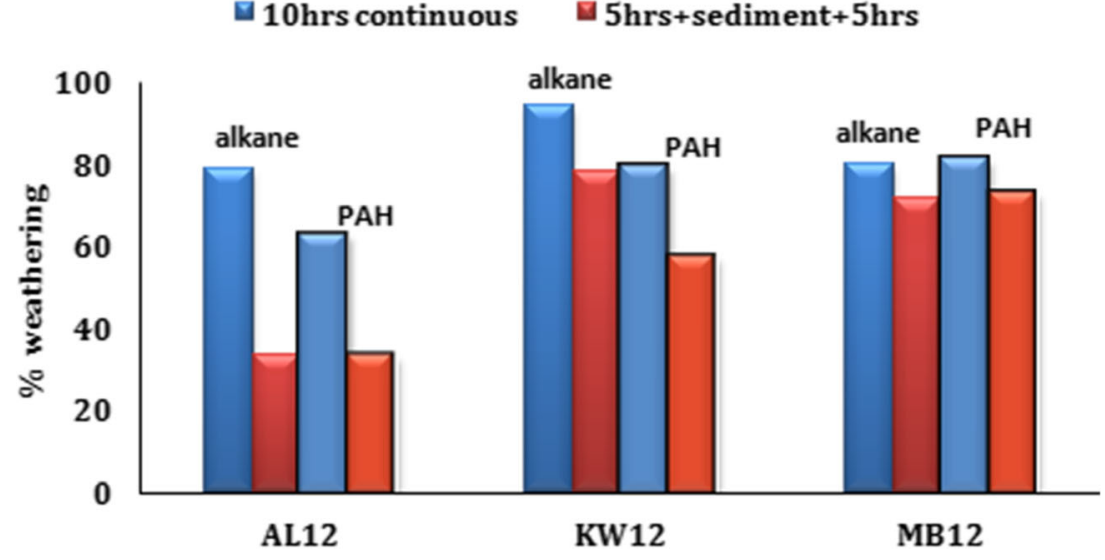

in n-alkane depletion. The highest depletion of naphthalene was noticed within $5 \mathrm{~h}$ of weathering when both sediment and oil were in equal amounts $\left(A L_{11}-05\right.$ in Fig. 6). A similar feature was not noticed when the ratios of oil and sediments were doubled $\left(\mathrm{AL}_{12}-05\right.$, $\mathrm{AL}_{21}-05$ in Fig. 6).

Overall, the rate of depletion of PAH compounds was slow when additional sediments were added to it. The percentage depletion of n-alkane and PAHs with 10-h continuous mixing and $10^{*} \mathrm{~h}$ mixing $(5 \mathrm{~h}$ mixing + sediment $+5 \mathrm{~h}$ mixing $)$ at constant OSR of $1: 2$ is shown in Fig. 8. This figure depicts that the depletion of both n-alkane and PAHs was high during $10-\mathrm{h}$ continuous mixing rather than $10^{*} \mathrm{~h}$ mixing $(5 \mathrm{~h}+$ sediment $+5 \mathrm{~h})$.

The PAH abundance profiles of $12 \mathrm{KW}$ OSAs are shown in Fig. 9. The compounds phenanthrene and methyl phenanthrenes, fluoranthene and pyrene are abundant in all the samples suggesting that these compounds were less weathered compared to the rest of the PAHs. Though a similar trend was observed in AL samples, naphthalene was quite low in $\mathrm{KW}$ samples for the sample combinations of $\mathrm{KW}_{11}$ and $\mathrm{KW}_{12}$, indicating that depletion of naphthalene was faster when oil and sediment quantities were equal or when sediment is double the quantity of oil.

Nevertheless, when the quantity of oil and sediment was equal but doubled (sediment was added additionally after 5 and $10 \mathrm{~h}$, $\left(\mathrm{KW}_{22}-10^{*}, \mathrm{KW}_{22}-20^{*}\right)$, the rate of depletion relatively reduced (Fig. 9). The additional sediments, which were added after 5 and $10 \mathrm{~h}$ of mixing time, might have acted as a barrier for the naphthalene to deplete and thus got trapped within the sediment.

In general, maximum depletion was observed in most of the PAHs within the first $5 \mathrm{~h}$ and $10 \mathrm{~h}$ mixing time irrespective of OSRs (Fig. 9: samples $\mathrm{KW}_{11}, \mathrm{KW}_{12}, \mathrm{KW}_{21}$ of $05 \mathrm{~h}$ and $10 \mathrm{~h}$ ). On the whole, it is apparent that the rate of depletion was low after additional sediments were added to it $\left(10^{*} \mathrm{~h}\right.$, 20 h mixing samples).

The PAH profiles of OSAs prepared with MB crude oil are shown in Fig. 10. As occurred in AL and KW OSAs, the compounds phenanthrene and methyl phenanthrenes, fluoranthene and pyrene were abundant in all samples, suggesting that these compounds were less weathered compared to the rest of the PAHs. The rate of depletion of naphthalene varied largely from one set of sample to another. The maximum depletion of naphthalene occurred in these OSAs at 10-h mixing time with OSR 1:2 and 2:1 (Fig. 10, sample ID $\mathrm{MB}_{12}-10, \mathrm{MB}_{21}-10$.

The maximum depletion of methyl chrysene and methyl pyrenes was occurred at $10-\mathrm{h}$ continuous mixing time for all OSAs (Figs. 7, 9 and 10). The highly alkylated C5-chrysenes were the most weathered species followed by C4-chrysenes, C3chrysenes, C2-chrysenes, C1-chrysenes and finally $\mathrm{C}_{0}$ chrysene. Yin et al. (2015) have shown the temporal evolution trend of $\mathrm{C}_{0}$ to $\mathrm{C}_{4}$ alkylated chrysenes in submerged BP oil spill natural residues as $\mathrm{C} 4>\mathrm{C} 3>\mathrm{C} 2>\mathrm{C} 1>\mathrm{C}$. . In the present study, also a similar trend was observed for all 36 OSAs. Overall, the results present that the chrysene weathering was predominantly due to physicochemical processes rather than biological degradation processes. In the case of alkylated pyrenes, the weathering trend seemed to be in reverse order of chrysenes. The weathering of $\mathrm{C}_{2}$-pyrene $<\mathrm{C}_{3^{-}}$pyrene $<\mathrm{C}_{4}$-pyrenes, whereas the $\mathrm{C}_{1}$ and $\mathrm{C}_{5}$ pyrenes do not follow this trend. Therefore, the dynamics of weathering of any individual PAH compound largely depends on the type and quantity of oil and the amount of sediment particles present in it. The physical properties of crude oils (such as density and viscosity) also can make a significant impact on the formation of OSAs and their weathering. For example, viscosity of the oil increases as it weathers, which decreases the ability of the oil to form small droplets (Delvigne and Sweeney, 1988). In addition, weathering of oil removes lighter components (e.g. n-alkanes, aromatics) while leaving heavier components, resulting in more concentrated asphaltene (Oudot et al. 1998). The increased asphaltene content together with increased viscosity forms stable emulsions (Bobra, 1991) and the increase in asphaltene concentration can also make weathered oil to attract charged clay particles (Bragg and Yang, 1995, Guyomarch et al. 2002).

The weathering percentage of both n-alkane and PAH compounds of all aggregates is illustrated in Fig. 11. The figure 

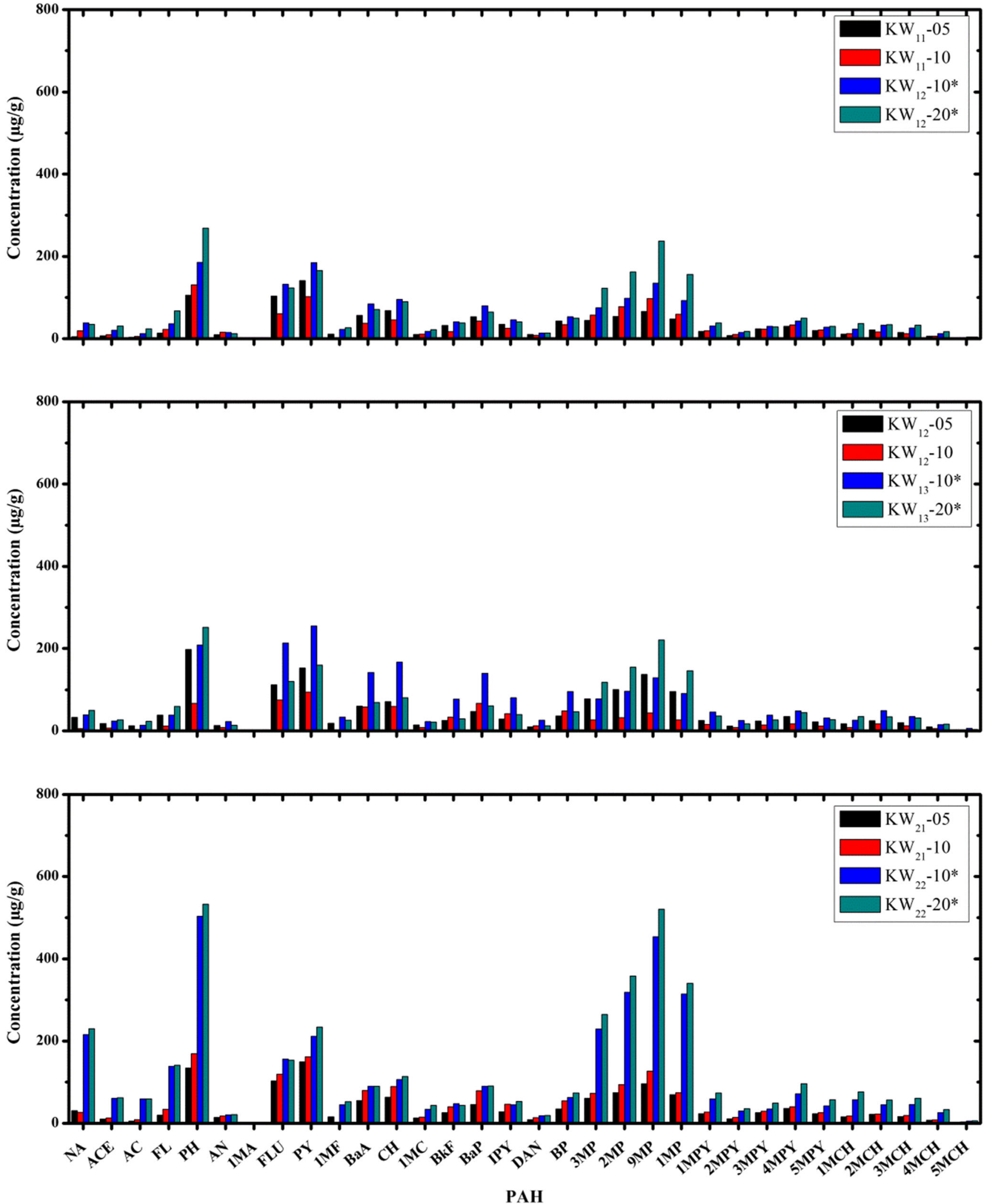

Fig. 9 Distribution of PAHs in KW OSAs

depicts that weathering trends of both n-alkanes and PAH were almost the same. The only difference is that PAHs of MB OSAs at 10 -h continuous mixing period were less weathered $(\sim 50 \%)$ compared to n-alkanes $(\sim 70 \%)$ (Fig. 11(a, b)). Figure 11 further 
reveals that the highest depletion has occurred at 10 -h continuous mixing time on each and every OSR (1:1_10, 1:2_10, 2:1_10), whereas occurrence of the lowest depletion percentage was different for different crude oils. For instance in AL OSAs, the
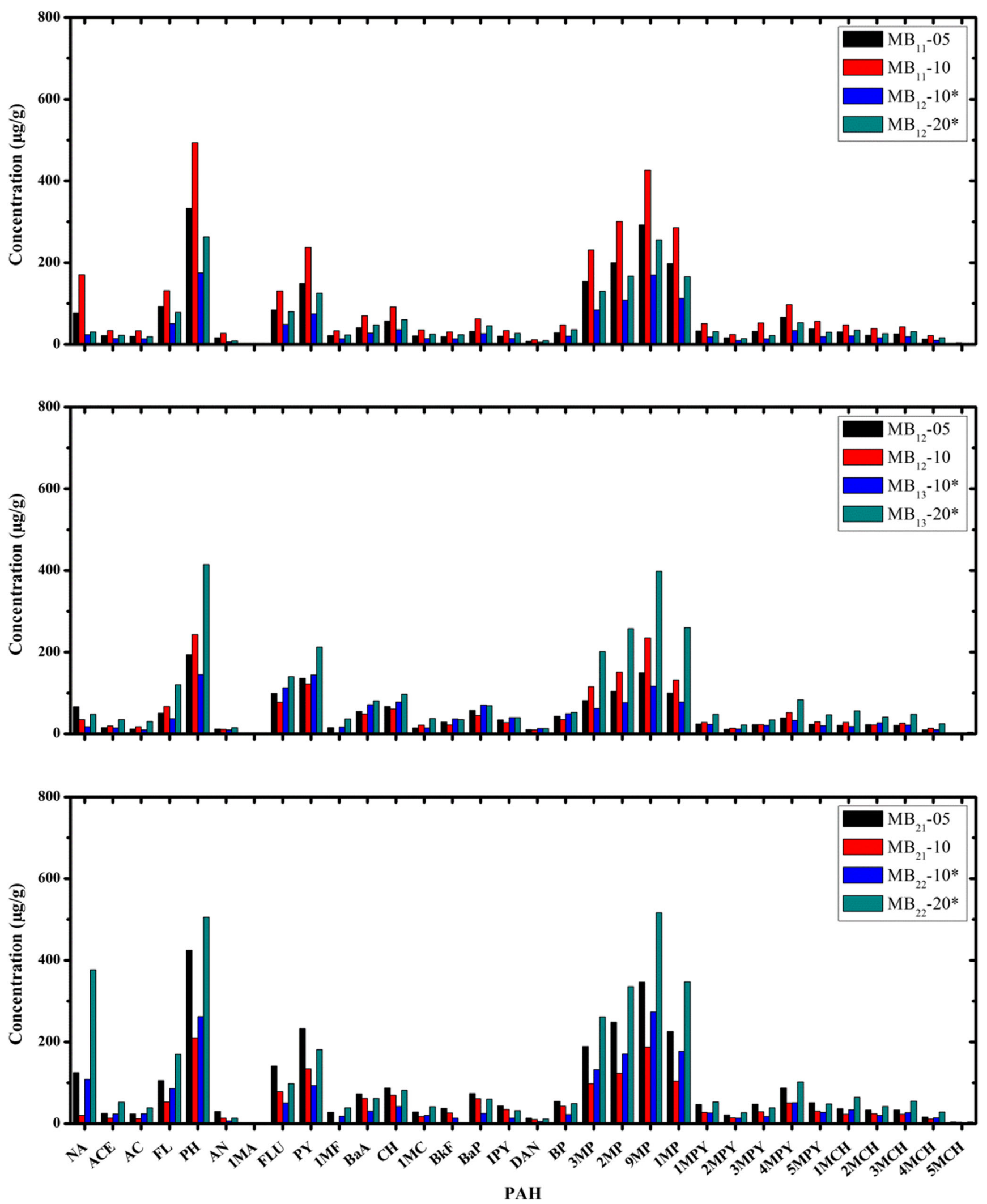

Fig. 10 Distribution of PAHs in MB OSAs 


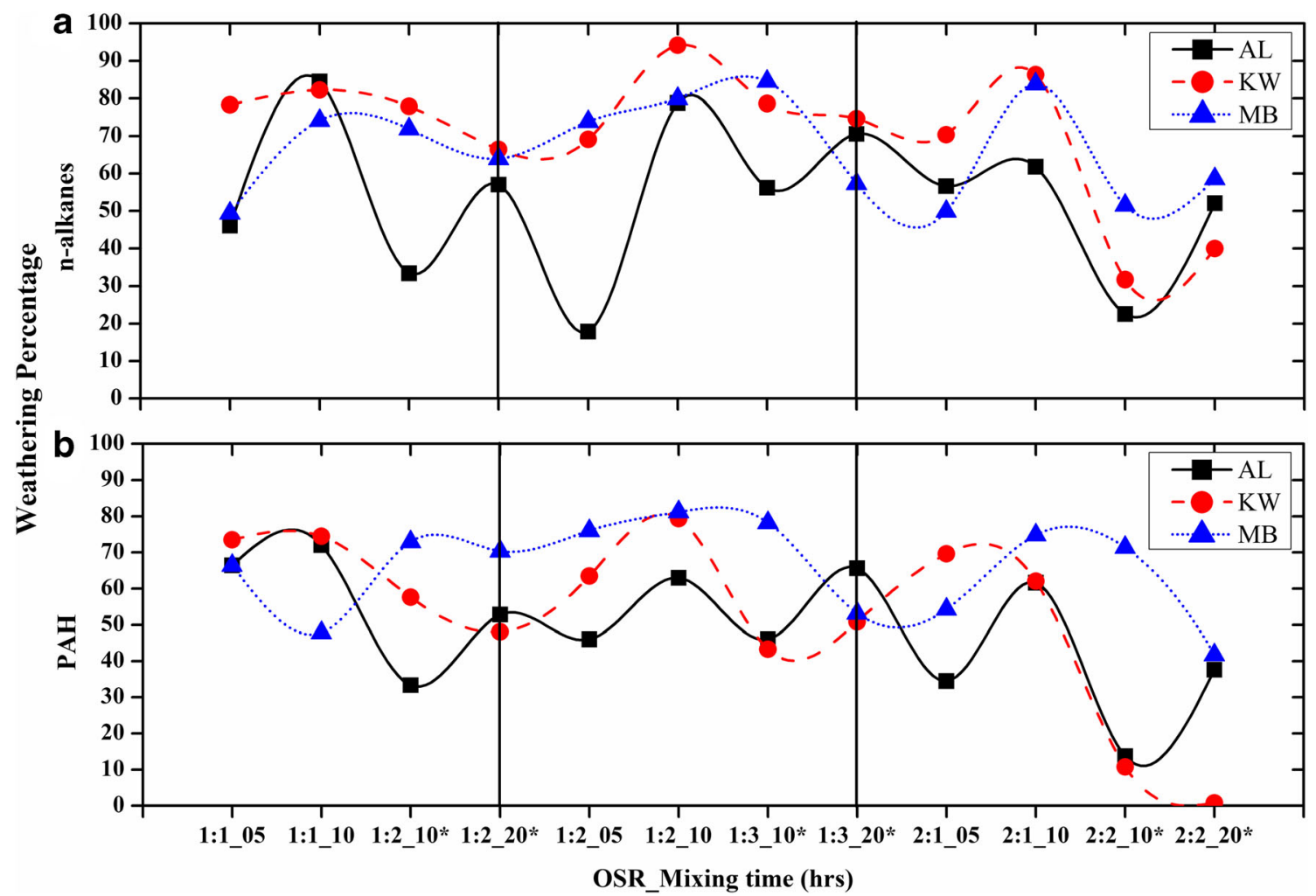

Fig. 11 Weathering percentage of n-alkanes and PAHs of all the OSAs at various OSRs

lowest depletion for both n-alkane and PAHs was at $10^{*} \mathrm{~h}$ weathering time (but in-between additional sediments were added after $5 \mathrm{~h}$ weathering time $\left(10^{*} \mathrm{~h}\right.$ mixing)). In the case of $\mathrm{KW}$ OSAs, the lowest weathering occurred at $20^{*} \mathrm{~h}$ for PAHs and $10^{*} \mathrm{~h}$ for $\mathrm{n}$-alkanes (but in-between additional sediments were added after $10 \mathrm{~h}$ and $5 \mathrm{~h}$ respectively). These results suggest that when sediment particles are added in between the experiment, these particles significantly adsorb the remnant hydrocarbons in the system and reduce rate of weathering while cleansing the system. When the low $\mathrm{L} / \mathrm{H}$ and $\mathrm{PH} / \mathrm{AN}$ ratios and high FLU/ PY ratios were compared with those of the reference crude oil, we observed that maximum depletion has occurred for the LMW compounds (Table 3).

Based on Baumard et al. (1998), we have categorized the PAH levels in all 36 OSAs as follows: if the PAH concentration is below $100 \mathrm{ng} / \mathrm{g}$ of dry weight, it is considered low PAH pollution, $100-1000 \mathrm{ng} / \mathrm{g}$ as moderate, $1000-5000 \mathrm{ng} / \mathrm{g}$ as high and above $5000 \mathrm{ng} / \mathrm{g}$ as very high $\mathrm{PAH}$ pollution. The PAH concentrations of all 36 OSAs were much higher than $5000 \mathrm{ng} / \mathrm{g}$ indicating that these OSAs are highly polluted even after serial weathering experiments.

\section{Conclusions}

Laboratory experiments were conducted to understand the OSA formation in ambient condition as well as by adding additional sediments (NIST SRM-1944) to investigate the influence of OSAs at different weathering periods. A total of 36 OSAs were prepared with three different crude oils under different mixing conditions. All the samples were processed and analysed through GCMS to quantify the n-alkanes and PAHs of the OSAs.

The GCMS analysis of OSAs revealed that the range of total $\mathrm{n}$-alkanes $\left(\mathrm{C}_{9}\right.$ to $\left.\mathrm{C}_{40}\right)$ varied from $9584.7 \mu \mathrm{g} / \mathrm{g}\left(\mathrm{KW}_{12^{-}}\right.$ 10) to $183,213 \mu \mathrm{g} / \mathrm{g}\left(\mathrm{AL}_{12}-05\right)$ and the total PAHs from $849.87 \mu \mathrm{g} / \mathrm{g}\left(\mathrm{KW}_{12}-10\right)$ to $5398 \mu \mathrm{g} / \mathrm{g}\left(\mathrm{AL}_{22}-10^{*}\right)$. Weathering of n-alkane compounds varied from $17.87 \%$ $\left(\mathrm{AL}_{12}-05\right)$ to $94.18 \%\left(\mathrm{KW}_{12}-10\right)$ and $\mathrm{PAH}$ compounds from $1 \%\left(\mathrm{KW}_{22}-20^{*}\right)$ to $\left.81.2 \%\left(\mathrm{MB}_{12}-10\right)\right)$. The highest depletion of $\mathrm{n}$-alkane and PAHs occurred over $10 \mathrm{~h}$ of continuous mixing time for all 36 OSAs, irrespective of OSRs. The rate of weathering of $n$-alkane and PAHs reduced when additional sediments were added in between the experiments, due to the absorbance of available hydrocarbons in the system. It is evident from visual microscopic images that the size of OSAs increased manifold due to addition of sediments (10-h and 20$\mathrm{h}$ mixing) in between the experiment. For example, $\mathrm{AL}_{21}-05$ samples having OSA size of $0.25 \mathrm{~mm}$ increased to $1.66 \mathrm{~mm}$ in $\mathrm{AL}_{22}-10^{*}$ sample when the sediment was added over the ambient condition after $5 \mathrm{~h}$ of weathering. Each crude oil sample was having different sizes of aggregates, which were altered by the interfacial forces between oil and sediment and also depending on environmental conditions such as mixing time. 
The calculated diagnostic ratios of $\mathrm{PAHs}$ such as $\mathrm{L} / \mathrm{H}, \mathrm{PH} /$ AN, FLU/PY and WI revealed depletion of low molecular weight components than high molecular weight components. The total concentration of PAHs found in the weathered OSAs was greater than $5000 \mathrm{ng} / \mathrm{g}$, indicating high $\mathrm{PAH}$ pollution. Though the formation of OSAs helps in cleaning the spill sites temporarily, their ultimate fate in the marine environment is either getting buried in the bottom sediments or reaching the shore. If effective and quick cleaning remediation measures are not followed, there could be a severe threat to the marine ecosystem due to these OSAs as well.

Supplementary Information The online version contains supplementary material available at https://doi.org/10.1007/s11356-020-11813-w.

Acknowledgements The authors thank the Director, CSIR-National Institute of Oceanography, Goa, for permitting to carry out this work. We acknowledge Dr. Ravail Singh for providing the microscope facility. We also thank Athish, Sonam and Chayanika for their support during sample processing. This is CSIR-NIO contribution number 6638.

Authors' contributions VS - concept of the work, funding acquisition, execution of the experiments, analysis, interpretation of data, and finalization of manuscript

SS - experiments, data processing, drawing figures, initial draft of the manuscript

$\mathrm{RB}$ - conceptualization, interpretation of data, preparation of initial draft of the manuscript

PV - initial draft of the manuscript, review and editing of the manuscript

Funding information This study is funded by the Department of Science and Technology through Climate Change Programme to VS.

Data availability The datasets used and/or analysed during the current study are available from the corresponding author on reasonable request.

\section{Compliance with ethical standards}

Conflict of interest The authors declare that they have no competing interests.

Ethics approval and consent to participate Not applicable

Consent for publication Not applicable

\section{References}

Ajijolaiya LO, Hill PS, Khelifa A, Islam RM, Lee K (2006) Laboratory investigation of the effects of mineral size and concentration on the formation of oil-mineral aggregates. Mar Pollut Bull 52:920-927. https://doi.org/10.1016/j.marpolbul.2005.12.006

Al-Yakoob S, Saeed T, Al-Hashash H (1993) Polycyclic aromatic hydrocarbons in edible tissue offish from the Gulf after the 1991 oil spill. Mar Pollut Bull 27:297-301

Al-Yakoob, S.N., Saeed, T. and Al-Hashash, H. (1994) Polycyclic aromatic hydrocarbons in fish:exposure assessment for Kuwaiti consumers after the Gulf oil spill of 1991. Environment International 20 (2), 221-227

Bandara UC, Yapa PD, Xie H (2011) Fate and transport of oil in sediment laden marine waters. J Hydro-environment Res 5:145-156. https:// doi.org/10.1016/j.jher.2011.03.002

Baumard P, Budzinski H, Garrigues P, Sorbe JC, Burgeot T, Bellocq J (1998) Concentrations of PAHs (polycyclic aromatic hydrocarbons) in various marine organisms in relation to those in sediments and to trophic level. Mar Pollu Bull 36:951-960

Bobra M (1991) Water-in-oil emulsification: a physicochemical study. Int Oil Spill Conf Proc 1991:483-488

Bragg JR, Owens EH (1995) Shoreline cleansing by interactions between oil and fine mineral particles. In International Oil Spill Conference Proceedings 1:219-227. https://doi.org/10.7901/2169-3358-1995$1-219$

Bragg, J. R and Yang, S. H. (1995). Clay-oil flocculation and its role in natural cleansing in Prince William Sound following the Exxon Valdez oil spill. In P. Wells, J. Butler, and J. Hughes (Eds.), Exxon Valdez Oil Spill: Fate and Effects in Alaskan Waters (pp. 178-214). West Conshohocken, PA: ASTM International. https:// doi.org/10.1520/STP19864S397-405. 10.1016/S0025-326X(03) 00209-1

Cao, B., Nagarajan, K., \& Loh, K. C. (2009). Biodegradation of aromatic compounds: current status and opportunities for biomolecular approaches. Applied Microbiology and Biotechnology, 85, 207-228.

Delvigne GAL, Sweeney CE (1988) Natural dispersion of oil. Oil Chem Pollut 4:281-310

Deng W, Li XG, Li SY, Ma YY, Zhang DH (2013) Source apportionment of polycyclic aromatic hydrocarbons in surface sediment of mud areas in the East China Sea using diagnostic ratios and factor analysis. Mar Pollut Bull 70:266-273. https://doi.org/10.1016/j. marpolbul.2013.02.032

Fingas M (2011) Oil spill science and technology. Elsevier, Amsterdam

Gong Y, Zhao X, Cai Z, O'Reilly SE, Hao X, Zhao D (2014) A review of oil, dispersed oil and sediment interactions in the aquatic environment: influence on the fate, transport and remediation of oil spills. Mar Pollut Bull 79:16-33. https://doi.org/10.1016/j.marpolbul. 2013.12.024

Gustitus SA, John GF, Clement TP (2017) Effects of weathering on the dispersion of crude oil through oil-mineral aggregation. Sci Total Environ 587-588:36-46. https://doi.org/10.1016/j.scitotenv.2017. 02.044

Guyomarch, J., Le Floch, S., Merlin, F.-X (2002) Effect of suspended mineral load, water salinity and oil type on the size of oil-mineral aggregates in the presence of chemical dispersant spill. Sci Technol Bull 8:95-100. https://doi.org/10.1016/S1353-2561(02)00118-4

Han Y, Nambi IM, Prabhakar Clement T (2018) Environmental impacts of the Chennai oil spill accident - a case study. Sci Total Environ 626:795-806

Ho SJ, Wang CY and Luo YM (2015) GC-MS analysis of two types of mixed oils, a comparison of composition and weathering patterns. Mar Pollut Bull 96(1-2):271-278. https://doi.org/10.1016/j. marpolbul.2015.05.013

Hospital A, Stronach J, Matthieu J (2016) A review of oil mineral aggregates formation mechanisms for the Salish Sea and the Lower Fraser River, in: 39th Arctic and Marine Oil Spill Technical Seminar, At Halifax, Nova Scotia, Canada pp 434-454

Karami A, Christianus A, Ishak Z, Shamsuddin ZH, Masoumian M, Courtenay SC (2012) Use of intestinal Pseudomonas aeruginosa in fish to detect the environmental pollutant benzo [a] pyrene. J Hazard Mater 215-216:108-114

Khelifa A, Fieldhouse B, Pjontek D, Wang Z, Yang C, Fingas M, Brown CE, Gamble L (2007) A laboratory study on formation of oil-SPM aggregates using the NIST standard reference material 1941b, in: 30th Arctic and Marine Oilspill Program, AMOP Technical Seminar, Environment Canada, Ottawa. ON pp 35-48 
Khelifa A, Stoffyn-Egli P, Hill PS, Lee K (2002) Characteristics of oil droplets stabilized by mineral particles: effects of oil type and temperature. Spill Sci Technol Bull 8:19-30. https://doi.org/10.1016/ S1353-2561(02)00117-2

Khelifa A, Stoffyn-Egli P, Hill PS, Lee K (2005) Effects of salinity and clay type on oil-mineral aggregation. Mar Environ Res 59:235-254. https://doi.org/10.1016/j.marenvres.2004.05.003

Khelifa A, Brown CE, Chun M, and Eubank JLE 2008) Physical properties of oil-SPM aggregates: Experiments with the NIST Standard Reference Material 1941b. Proceedings of the 31st AMOP Technical Seminar on Environmental Contamination and Response, Vol. 1

Lee RF, Page DS (1997) Petroleum hydrocarbons and their effects in subtidal regions after major oil spills. Mar Pollut Bull 34:928-940. https://doi.org/10.1016/S0025-326X(97)00078-7

Lee K, Lunel T, Wood P, Swannell R, Stoffyn-Egli P (1997) Shoreline cleanup by acceleration of clay-oil flocculation processes. International Oil Spill Conference Proceedings 1997(1):235-240. https://doi.org/10.7901/2169-3358-1997-1-235

Lee, K, Stoffyn-Egli, P, Wood, P. A, and Lunel, T, (1998). Formation and structure of oil-mineral fines aggregates in coastal environments. Canada, 911-921. Web. Conference proceedings of Arctic and marine oilspill program technical seminar, Edmonton (Canada), 10-12 Jun 1998

Li Z, Kepkay P, Lee K, King T, Boufadel MC, Venosa AD (2007) Effects of chemical dispersants and mineral fines on crude oil dispersion in a wave tank under breaking waves. Mar Pollut Bull 54:983-993. https://doi.org/10.1016/j.marpolbul.2007.02.012

Liu F, Liu J, Chen Q, Wang B, Cao Z, (2013) Pollution characteristicsand ecological risk of polycyclic aromatic hydrocarbons (PAHs)in surface sediments of the southern part of the Haihe Riversystem in China. Chin Sci Bull 58:3348-3356

Liu Z, Liu J, Zhu Q, Wu W (2012) The weathering of oil after the Deepwater Horizon oil spill: insights from the chemical composition of the oil from the sea surface, salt marshes and sediments. Environ Res Lett 7:35302. https://doi.org/10.1088/1748-9326/7/3/035302

Loh A, Shim WJ, Ha SY, Yim UH (2014) Oil-suspended particulate matter aggregates: formation mechanism and fate in the marine environment. Ocean Sci J 49:329-341. https://doi.org/10.1007/ s12601-014-0031-8

Moreira ÍTA, Oliveira OMC, Silva CS, Rios MC, Queiroz AFS, Assunção RV, Carvalho APN (2015) Chemometrics applied in laboratory study on formation of oil-spm aggregates (OSAs) - a contribution to ecological evaluation. Microchem J 118:198-202. https://doi.org/10.1016/j.microc.2014.09.007

NRC (2003) Oil in the sea III: inputs, fates, and effects. The National Academies Press, Washington, DC. https://doi.org/10.17226/10388

Oudot J, Merlin F, Pinvidic P (1998) Weathering rates of oil components in a bioremediation experiment in estuarine sediments. Mar Environ Res 45:113-125

Owens EH, Lee K (2003) Interaction of oil and mineral fines on shorelines: review and assessment. Mar Pollut Bull 47:9-12

Payne JR, Clayton JR, Kirstein BE (2003) Oil/suspended particulate material interactions and sedimentation. Spill Sci. Technol. Bull. 8: 201-221. https://doi.org/10.1016/S1353-2561(03)00048-3

Reddy CM, Quinn JG (1999) GC-MS analysis of total petroleum hydrocarbons and polycyclic aromatic hydrocarbons in seawater samples after the North Cape oil spill. Mar Pollut Bull 38:126-135. https:// doi.org/10.1016/S0025-326X(98)00106-4

Rengarajan T, Rajendran P, Nandakumar N, Lokeshkumar B, Rajendran P, Nishigaki I (2015) Exposure to polycyclic aromatichydrocarbons with special focus on cancer. Asian Pac J TropBiomed 5:182-189

Sammarco PW, Kolian SR, Warby RAF, Bouldin JL, Subra WA, Porter SA (2013) Distribution and concentrations of petroleum hydrocarbons associated with the BP/Deepwater Horizon oil spill, Gulf of
Mexico. Mar Pollut Bull 73:129-143. https://doi.org/10.1016/j. marpolbul.2013.05.029

Sørensen L, Melbye AG, Booth AM (2014) Oil droplet interaction with suspended sediment in the seawater column: influence of physical parameters and chemical dispersants. Mar Pollut Bull 78:146-152. https://doi.org/10.1016/j.marpolbul.2013.10.049

Spaulding ML (1988) A state-of-the-art review of oil spill trajectory and fate modeling. Oil Chem. Pollut. 4:39-55

Sun J, Zhao D, Zhao C, Liu F and Zheng X (2013) Investigation of the kinetics of oil-suspended particulate matter aggregation. Mar Pollut Bull 76(1-2):250-257. https://doi.org/10.1016/j.marpolbul.2013. 08.030

Sun J, Khelifa A, Zhao C, Zhao D, Wang Z (2014) Laboratory investigation of oil-suspended particulate matter aggregation under different mixing conditions. Sci Total Environ 473-474:742-749. https:// doi.org/10.1016/j.scitotenv.2013.12.078

Sun J, Khelifa A, Zheng X, Wang Z, So LL, Wong S, Yang C, Fieldhouse B (2010) A laboratory study on the kinetics of the formation of oilsuspended particulate matter aggregates using the NIST-1941b sediment. Mar Pollut Bull 60:1701-1707. https://doi.org/10.1016/j. marpolbul.2010.06.044

Sun J, Zheng X (2009) A review of oil-suspended particulate matter aggregation-a natural process of cleansing spilled oil in the aquatic environment. J Environ Monit 11:1801-1809. https://doi.org/10. 1039/b904829b

Suneel V, Vethamony P, Zakaria MP, Naik BG, Prasad KVSR (2013) Identification of sources of tar balls deposited along the Goa coast, India, using finger- printing techniques. Mar Pollut Bull 70:81-89

Suneel V, Vethamony P, Naik BG, Vinod Kumar K, Sreenu L, Samiksha SV, Yunus Tai and Sudheesh K (2014) Source investigation of the tar balls deposited along the Gujarat coast, India using Chemical fingerprinting and transport modeling techniques. Environ Sci Technol 48:11343-11351

Suneel, V., Vethamony P, Naik BG, Krishna MS, Jadhav L (2015) Identifying the source of tar balls deposited along the beaches of Goa in 2013 and comparing with historical data collected along the west coast of India. Sci Total Environ 527-528:313-321

Venosa AD, Holder EL (2013) Determining the dispersibility of South Louisiana crude oil by eight oil dispersant products listed on the NCP Product Schedule. Mar Pollut Bull 66:73-77. https://doi.org/ 10.1016/j.marpolbul.2012.11.009

Wade TL, Sericano JL, Sweet ST, Knap AH, Guinasso NL (2016) Spatial and temporal distribution of water column total polycyclic aromatic hydrocarbons $(\mathrm{PAH})$ and total petroleum hydrocarbons (TPH) from the Deepwater Horizon (Macondo) incident. Mar Pollut Bull 103: 286-293. https://doi.org/10.1016/j.marpolbul.2015.12.002

Wang Z, Fingas M, Li K (1994) Fractionation of a light crude oil and identification and quantitation of aliphatic, aromatic, and biomarker compounds by GC-FID and GC-MS, part I. J Chromatogr Sci 32: 361-366. https://doi.org/10.1093/chromsci/32.9.361

Yan J, Liu J, Shi X, You X, Cao Z (2016) Polycyclic aromatic hydrocarbons (PAHs) in water from three estuaries of China: distribution, seasonal variations and ecological risk assessment. Mar Pollut Bull 109:471-479. https://doi.org/10.1016/j.marpolbul.2016.05.025

Yang C, Zhang G, Wang Z, Yang Z, Hollebone B, Landriault M, Shah K, Brown CE (2014) Development of a methodology for accurate quantitation of alkylated polycyclic aromatic hydrocarbons in petroleum and oil contaminated environmental samples. Anal Methods 6: 7760-7771. https://doi.org/10.1039/C4AY01393J

Yin F, John GF, Hayworth JS, Clement TP (2015) Long-term monitoring data to describe the fate of polycyclic aromatic hydrocarbons in Deepwater Horizon oil submerged off Alabama's beaches. Sci Total Environ 508:46-56. https://doi.org/10.1016/j.scitotenv.2014. 10.105

Zakaria MP, Okuda T, Takada H (2001) Polycyclic aromatic hydrocarbon (PAHs) and hopanes in stranded tar-balls on the coasts of 
Peninsular Malaysia: applications of biomarkers for identifying sources of oil pollution. Mar Pollut Bull 42:1357-1366. https:// doi.org/10.1016/S0025-326X(01)00165-5

Zakaria MP, Takada H, Tsutsumi S, Ohno K, Yamada J, Kouno E, Kumata H (2002) Distribution of polycyclic aromatic hydrocarbons (PAHs) in rivers and estuaries in Malaysia: a widespread input of petrogenic PAHs. Environ Sci Technol 36:1907-1918. https://doi. org/10.1021/es011278\%2B

Zhang J, Liu G, Yuan Z, Wang R (2014) Levels and distributions of polycyclic aromatic hydrocarbons (PAHs) in middle reach of
Huaihe River. China: anthropogenic influences and ecological risks Nat Hazards 74:705-716. https://doi.org/10.1007/s11069-014$1210-8$

Zelinkova Z, Wenzl T (2015) The occurrence of 16EPA PAHs in food - a review. Polycycl Aromat Compd 35(2-4):248-284. https://doi.org/ 10.1080/10406638.2014.918550

Publisher's note Springer Nature remains neutral with regard to jurisdictional claims in published maps and institutional affiliations. 